\title{
Absence of Glia Maturation Factor Protects from Axonal Injury and Motor Behavioral Impairments after Traumatic Brain Injury
}

\author{
Govindhasamy Pushpavathi Selvakumar ${ }^{1,2,3}$, Mohammad Ejaz Ahmed ${ }^{1,2,3}$, Shankar S. Iyer ${ }^{1,2,3}$, \\ Ramasamy Thangavel ${ }^{1,2,3}$, Duraisamy Kempuraj ${ }^{1,2,3}$, Sudhanshu P. Raikwar ${ }^{1,2,3}$, Kieran Bazley ${ }^{2,3}$, \\ Kristopher $\mathrm{Wu}^{2,3}$, Asher Khan ${ }^{2,3}$, Klaudia Kukulka ${ }^{2,3}$, Bret Bussinger, ${ }^{2,3}$, Smita Zaheer ${ }^{2,3}$, Casey Burton ${ }^{4}$, \\ Donald James ${ }^{4}$ and Asgar Zaheer ${ }^{1,2,3 *}$ \\ ${ }^{1}$ Harry S. Truman Memorial Veterans Hospital, Columbia, Missouri 65211, \\ ${ }^{2}$ Department of Neurology, and ${ }^{3}$ Center for Translational Neuroscience, School of Medicine, University of Missouri, \\ Columbia, Missouri 65211, ${ }^{4}$ Phelps Health, Rolla, Missouri 65401, USA
}

\begin{abstract}
Traumatic brain injury (TBI) causes disability and death, accelerating the progression towards Alzheimer's disease and Parkinson's disease (PD). TBI causes serious motor and cognitive impairments, as seen in PD that arise during the period of the initial insult. However, this has been understudied relative to TBI induced neuroinflammation, motor and cognitive decline that progress towards PD. Neuronal ubiquitin-C-terminal hydrolaseL1 (UCHL1) is a thiol protease that breaks down ubiquitinated proteins and its level represents the severity of TBI. Previously, we demonstrated the molecular action of glia maturation factor (GMF); a proinflammatory protein in mediating neuroinflammation and neuronal loss. Here, we show that the weight drop method induced TBI neuropathology using behavioral tests, western blotting, and immunofluorescence techniques on sections from wild type (WT) and GMF-deficient (GMF-KO) mice. Results reveal a significant improvement in substantia nigral tyrosine hydroxylase and dopamine transporter expression with motor behavioral performance in GMF-KO mice following TBI. In addition, a significant reduction in neuroinflammation was manifested, as shown by activation of nuclear factor-kB, reduced levels of inducible nitric oxide synthase, and cyclooxygenase-2 expressions. Likewise, neurotrophins including brain-derived neurotrophic factor and glial-derived neurotrophic factor were significantly improved in GMF-KO mice than WT $72 \mathrm{~h}$ post-TBI. Consistently, we found that TBI enhances GFAP and UCHL-1 expression and reduces the number of dopaminergic TH-positive neurons in WT compared to GMF-KO mice $72 \mathrm{~h}$ post-TBI. Interestingly, we observed a reduction of THpositive tanycytes in the median eminence of WT than GMF-KO mice. Overall, we found that absence of GMF significantly reversed these neuropathological events and improved behavioral outcome. This study provides evidence that PD-associated pathology progression can be initiated upon induction of TBI.
\end{abstract}

Key words: Traumatic brain injury, Neuroinflammation, Glia maturation factor, Parkinson's disease, Motor behavior

Submitted April 26, 2020, Revised June 9, 2020,

Accepted June 9, 2020

* To whom correspondence should be addressed. TEL: 573-882-5386, FAX: 573-882-5386 e-mail: zaheera@health.missouri.edu

\section{INTRODUCTION}

Traumatic brain injury (TBI) is a leading cause of disability, death, and approximately 50 million people experience TBI [1]. More than 1.7 million people have TBI in the United States of America [2-4], and the economic burden from TBI has been estimated to be more than $\$ 400$ billion annually [5-7]. Worldwide, the occurrence of TBI is increasing, particularly in developing 
countries [8]. TBI affects veterans, professional athletes, and boxers that cause decelerating muscular movements (athetosis) occasionally combined with difficulty in speech, tremors of the hands, gait disturbance, drowsiness and mental illness [9]. TBI encompasses a series of events that cause both physical and cognitive impairments that interfere with locomotor ability in normal life $[4,10$ 12]. TBI involves a mechanical injury that is the primary event followed by secondary damages that cause pathological changes at the site of injury, the penumbra or contusion region. The secondary damages including the inflammatory response, apoptosis, and breach of the blood-brain barrier (BBB), formation of edema, oxidative stress, and excitotoxic damage that leads to neuronal death [13-15]. Ubiquitin carboxy terminal hydrolase-1 (UCHL-1) is a multifactorial protein selectively expressed in neurons and GFAP is a glial filament protein specifically expressed by astrocytes. Both these proteins represent the severity of astrocyte mediated neuronal damages upon TBI $[16,17]$. Earlier studies have shown that TBI in WT mice activates the NF-kB pathway, but we would like to emphasize that the molecular responses to TBI mediated by GMF such as changes in NF-kB and neurotrophic factors have not been described before and are reported here for the first time. Recently, Mettang et al, reported that NF-kB activation aggravates and activates apoptosis mediated neuronal cell death that activates proinflammatory gene expression, severely causes behavioral impairments and increases mortality rate [18, 19]. Previous studies have shown that double peaks of increased NF-kB activity found in the subarachnoid hemorrhage [20], enhances astrocyte swelling mediated brain edema volume in TBI [21]. In addition, NF-kB activation selectively participates in neurotrophic factors expression such as neuronal growth factor (NGF), brain-derived neurotrophic factor (BDNF) and excitatory neurotransmitters [22, 23]. Enhanced expression of neurotrophic factors activates NF-kB [24-26]. However, the pathophysiology of TBI is complex, and the mechanism of neurodegeneration in TBI remains poorly understood. The consequences of TBI cause secondary complications that are closely linked with the advancement to neurodegenerative diseases including Parkinson's disease (PD), dementia pugilistica (DP) and Alzheimer's disease (AD) among other pathologies [2729]. PD is an age-associated neurodegenerative disorder, pathologically characterized by a loss of dopaminergic (DAnergic) neurons and subsequent decline of dopamine concentration in the nigrostriatal region of midbrain [30].

TBI causes focal brain tissue damage, diffused axonal injury and suppresses the electrical and chemical transmission between the neuronal cells in the brain [31]. These neuro-anatomical alterations have been examined through epigenetic and behavioral studies $[32,33]$. There are two major pathological markers identified and recognized that contribute to the development of PD or PD like pathology such as DAnergic system degeneration and $\alpha$-synuclein inclusions in the SN region of the brain $[34,35]$. However, increasing evidence suggests that dysfunctions of the DAnergic system may be a significant contributing mechanism for behavioral and cognitive deficits after TBI $[36,37]$. Alterations in the DAnergic signaling pathway may be a potential mechanism for the persistent cognitive dysfunction seen after TBI [31]. Primarily, TBI causes cognitive impairments due to damage and loss of hippocampal [38, 39], and frontal cortex [40] neurons that affect neural transmission between these regions to striatum [41]. Termination or fluctuations of dopamine neural transmission from these regions lead to impairments in attention, executive function, learning, memory, and motor decline [42-45]. Even though restoration and recovery are possible, certain factors affect the recovery rate such as different personal and social influences [12].

Experimental studies have demonstrated that small protein molecules play a crucial role in several intracellular functional deteriorations, which are closely involved in a number of pathophysiological changes. Currently, a number of studies have investigated the novel therapeutic targets of small proteins with essential biological properties to halt the secondary consequences associated with TBI. One of these small proteins is the glia maturation factor (GMF; 17-kDa) a neuroinflammatory protein, which was first isolated, purified, and characterized in our laboratory [4648]. GMF is abundantly present in central nervous system and principally expressed by the neuronal populations such as neurons and astroglia $[47,49,50]$. The expression of GMF was increased with intracellular stress and rapidly phosphorylated by protein kinases at various phosphorylation sites [51-53]. The present study was undertaken to better understand the mechanisms of action of GMF on the pathological events that are associated with TBI leading to the development of movement disorder like PD, and understanding how GMF mediates neuroinflammation and influences behavioral deficits in mice.

\section{MATERIALS AND METHODS}

\section{Animals}

Wild type (WT) C57BL/6 mice (25 30 gm), aged between 10 12 weeks, were maintained and housed at The University of Missouri, Columbia laboratory animal care facility, and they were used in accordance with the guidelines approved by the IACUC and National Institutes of Health. The C57BL/6 global glia maturation factor knockout (GMF-KO) mice were generated in our laboratory [50, $54,55]$, and colonies of these mice were permanently sustained in our laboratory for our studies. Mice were housed four per cage and 
maintained under a $12: 12 \mathrm{~h}$ light/dark cycle at $21 \pm 1^{\circ} \mathrm{C}$ and $50 \pm 5 \%$ humidity. Standard laboratory diet and drinking water were available ad libitum.

\section{Closed head injury induced by a weight-drop method}

TBI experiment was performed using the closed-head weight drop model as reported previously $[56,57]$ with a few modifications. In brief, mice were deeply anesthetized with $2 \%$ Isoflurane and $\mathrm{O}_{2}$, allowed to respire spontaneously without tracheal intubation. The WT and GMF-KO mice were subjected to TBI or to sham-treatment, where mice underwent identical surgical procedures. The severity of brain injury was a determinant of weight and the height from which it is dropped, that can range from mild to severe. In the present study, mice were subjected to mildTBI (mTBI) by placement on a platform covered by foam. The head was not fixed to enable a predominantly diffuse injury induced by a shearing force, to mimic real-life accidents. The head injury was induced by using the concussive head trauma device, as described previously $[58,59]$ as shown in schematic diagram (Fig. 1A). The device is a hollow metal tube that was placed vertically above the head of mice. An iron metal weight ( $3 \mathrm{~mm}$ diameter, $35 \mathrm{gm}$ ) that drops freely from a height of $50 \mathrm{~cm}$ was used to induce high acceleration and upon impact cause a shearing in the target area of injury as needed which was identified as the right frontal anterior region of the brain area $(1.5 \mathrm{~mm}$ lateral to the midline in front of the coronal plane). For the sham-operated control mice, outer skin was opened and the skull was exposed under anesthesia, then the skin incision was closed with silk sutures without brain injury. Body temperature was maintained at $37^{\circ} \mathrm{C}$ throughout all proce- dures using a small animal temperature control chamber and immediately returned to the home cage after complete recovery from anesthesia. This model simulates traumatic brain injuries seen in road accidents or falls, as it imparts a diffuse injury.

\section{Behavioral assessments}

At the end of the experiment, all the behavioral performances were assessed between 09:00 AM - 5:00 PM at the regulated room temperature in a quiet room as detailed before $[57,60]$. The laboratory-trained staff conducted all the behavioral performances and data analysis of the TBI and sham-operated control. We followed the procedure for the blinded behavioral assessments of both WT and GMF-KO mice after TBI induction as we have previously reported $[60,61]$.

\section{Tail suspension test}

The tail suspension test (TST) was used to assess the depressivemotor behavior in mice, as previously reported [62, 63]. In brief, experimental mice were individually suspended at the height of $50 \mathrm{~cm}$ from foam mat by using a piece of adhesive tape, approximately $2 \mathrm{~cm}$ from the tail tip of the mice. The immobility time was recorded during 3 minutes period.

\section{Hang test}

Neuromuscular impairment and motor coordination in mice were measured by hang test performance as described earlier [64, 65]. In brief, experimental mice were placed $50 \mathrm{~cm}$ from foam mat on a horizontal grid and the grid was gently inverted so that the mice were allowed to hang upside down. The grid was placed 50

\section{A Weight drop induced TBI model}

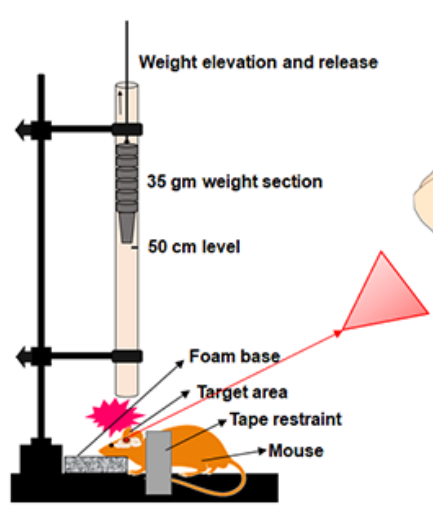

B

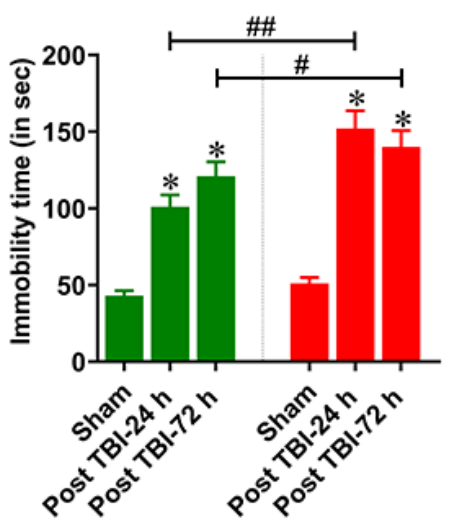

C

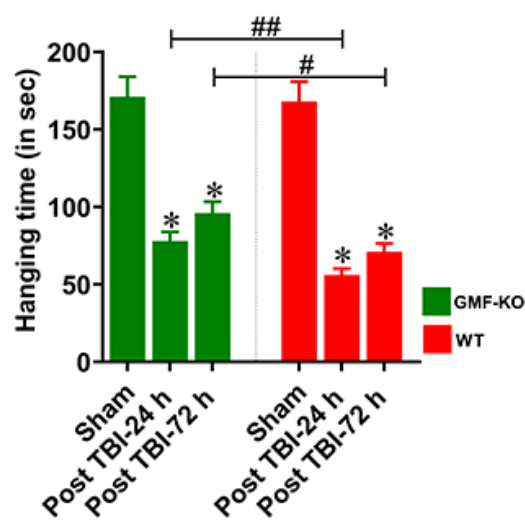

Fig. 1. Absence of GMF improves behavioral performance after weight drop induced TBI in mice. Induction of TBI by weight drop method in the cortical region (A) that significantly causes motor behavioral impairments in tail suspension test (B) and hang test (C) from WT and GMF-KO mice. The absence of GMF significantly reverses these behavioral abnormalities compared with WT TBI subjected mice. Values are presented as mean \pm SEM ( $\mathrm{n}=6$ ). ${ }^{*} \mathrm{p}<0.05$ control vs TBI subjected mice; ${ }^{*} \mathrm{p}<0.05$ and ${ }^{\# *} \mathrm{p}<0.01$ GMF-KO TBI subjected mice vs WT TBI subjected mice. 
$\mathrm{cm}$ above the foam mat to prevent the injury to the mouse when it falls. The total staying time until the mice lost their grasp was measured as hanging time.

\section{Nissl staining and measurement of contusion volume}

Nissl staining method was opted to measure the contusion volumes of TBI or sham-operated control mice, as reported previously $[66,67]$. Nissl staining was performed at different times such as post-TBI-24 $\mathrm{h}$ and post-TBI-72 $\mathrm{h}$ after experimental TBI. The brains of experimental mice were prefixed with a $4 \%$ paraformaldehyde solution. To freeze and cut the brain sections we used an Optimal-cutting temperature (OCT) embedding medium. Coronal sections (25 30 $\mu \mathrm{m}$-thick) were made in a cryostat (Leica Biosystems, Germany), and the sections were deeply washed with 1X PBS (ThermoScientific, Waltham, MA). The brain regions containing target lesions were collected every $200 \mathrm{mM}$. After sectioning, brain slices were deeply washed with PBS for 5 min, and stained with working buffer solution, which contains $0.1 \mathrm{M}$ acetic acid and 0.1 M sodium acetate (94:6) and Cresyl Violet acetate at a ratio of 5:1. Then the sections were dehydrated with $100 \%$ ethyl alcohol and mounted in gelatin-coated glass slides. After Nissl staining, the sections were digitized using a Nikon microscope and quantified by using ImageJ software (NIH, Bethesda, MD). Contusion volume was assessed based on the previous reports [68]. The contusion volume of the areas of the hemispheres were quantified by an investigator blinded to the TBI and non-TBI subjected animals ( $\mathrm{n}=6$ per group).

\section{Western blot}

The levels of protein expression was quantified by the Western blot method as we have described previously [69-71]. The extracted brain protein samples were equally loaded (ranging from $\sim 20$ to $35 \mu \mathrm{g})$ in each well, electrophoresed followed by transfer to polyvinylidene fluoride (PVDF) membrane. Immediately the membranes were blocked for $1 \mathrm{~h}$ at $4{ }^{\circ} \mathrm{C}$, then incubated overnight at $4^{\circ} \mathrm{C}$ with following primary antibodies diluted in blocking solution: Tyrosine hydroxylase (TH) (ThermoScientific, Cat No. P21962; 1:800), dopamine transporters (DAT) (ThermoScientific, Cat No. PA1-4656; 1:800), glial fibrillary acidic protein (GFAP; Cell Signaling Technology (CST), Beverly, MA, USA; Cat No. 12389S, 1:1,000), C-terminal hydrolase-L1 (UCH-L1; CST, Cat No. 13179S, 1: 800), total and p-NFkB (CST, Cat No. 3033S, 1:800), BDNF (CST, Cat No. 3897S, 1:800), GDNF (CST, Cat No. 3223S, 1:800), iNOS (CST, Cat No. 13120S, 1:800), COX-2(CST, Cat No. 12282S, 1:1,000) and $\beta$-actin (Sigma-Aldrich, Cat No. A2228, 1:1,000) at $4{ }^{\circ} \mathrm{C}$ overnight with gentle shaking. Subsequently, the membranes were washed and incubated with corresponding secondary antibodies (HRP- conjugated anti-rabbit or anti-mouse $\operatorname{IgG}$ ). The band signals were visualized by adding ECL reagent and densitometry analyses were performed.

\section{Immunofluorescence analysis}

Immunofluorescence double staining and positively stained cells were counted in the SN and STR region as described previously $[60,61,72]$. Midbrain tissues were collected from mice subjected to TBI or sham-operated control mice for immunofluorescence and performed as previously reported $[73,74]$. As we mentioned previously, brain sections were washed and blocked with blocking buffer (containing 1\% BSA in TBST) for 30 mins at $4{ }^{\circ} \mathrm{C}$. Following this the, sections were probed with the following primary antibodies: MAP2 (CST, Cat No. 8707S, 1:500); UCHL1 (1:500), NFL (CST, Cat No. 2837S, 1:500) and TH antibody (1:500) at $4^{\circ} \mathrm{C}$. These sections were then incubated with their matching Alexa flour conjugated secondary antibodies (Alexa Fluor 488; Cat No. A-11001, Alexa Fluor 568; Cat No. A-11004, ThermoScientific). Finally, stained sections were transferred and mounted on a gelatin-coated slide with coverslip glued with mounting medium containing DAPI (VECTASHIELD antifade, Vector Laboratories). Then the slides were examined and images were acquired under a Nikon fluorescent microscope and number of nigral TH positive dopaminergic neurons were determined as described previously [75-77]. To determine the TH-positive area and the axonal length of the dopaminergic neurons in the $\mathrm{SN}$ from immunostained sections, we used NIH ImageJ software. Results are expressed in arbitrary unit (AU) on analysis obtained from five different random fields and compared to controls.

For the confocal imaging, the immunofluorescent stained microscopic slides were examined and the images were acquired under a Leica TCP SP8 rapid laser scanning confocal microscope (Leica, Biosystems, Germany) as we demonstrated previously [69-71].

\section{Statistical analysis}

All the results obtained from the experiments were analyzed by GraphPad InStat 3 software. All the data are expressed as mean \pm SEM. To determine statistically significant differences we used a one-way analysis of variance (ANOVA) followed by TukeyKramer post hoc test. In addition, an unpaired $t$-test was performed when comparing only two groups. $\mathrm{p}<0.05$ was considered statistically significant in all the experiments in this study.

\section{RESULTS}

\section{GMF reduces behavioral performance in TBI mice}

Neuromotor behavioral impairment is a common sequela in 
weight drop induced TBI (Fig. 1A), as we determined by motor behavioral impairments in mice through assessing immobility time in tail suspension test (Fig. 1B) and hanging time in hang test (Fig. 1C). Results show a significant reduction of motor behavioral performance found in TBI subjected WT mice. Notably, we found that the absence of GMF in mice (GMF-KO mice) subjected to TBI showed a significant decrease in behavioral impairments at 24 $\mathrm{h}$ and $72 \mathrm{~h}$ post-TBI compared to WT mice. No significant differences were found between the sham-operated controls of WT and GMF-KO mice. These results indicate that GMF may be involved in the neuromotor behavioral performances in TBI induced mice through the neuroinflammatory sequence in the affected region of the brain.

\section{GMF augments TBI induced contusion volume and ampli- fies brain tissue damage}

The Nissl stained brain sections revealed that there was a significant cortical cell loss, which was examined by lack of cresyl violet staining and the representative images show contusion volumes following unilateral TBI in right hemisphere (Fig. 2A). Brain edema and contusion volume were assessed on day 3 after TBI, since weight drop induced more brain cortical tissue damage during this time (Fig. 2B). Quantitative bar graph shows that there were no significant differences in the contusion volume between the WT and GMF-KO mice after $24 \mathrm{~h}$ post-TBI. Meanwhile, the contusion volume significantly increased in WT mice compared to GMF-KO mice after $72 \mathrm{~h}$ post-TBI (Fig. 2C). No obvious brain contusion volume was observed in the sham-operated control group. However, GMF-KO mice showed less contusion volume compared with WT mic following $24 \mathrm{~h}$ and $72 \mathrm{~h} \mathrm{TBI}$.

\section{GMF attenuates TBI induced expression of dopaminergic markers in SN of midbrain}

Next, we examined the consequence of GMF on the expression of dopaminergic markers in mice brain after $72 \mathrm{~h}$ post-TBI. We examined TH (essential rate-limiting enzyme of catecholamine dopamine biosynthesis) and dopaminergic transporter DAT (a membrane-spanning protein that propels the catecholamine exchange between the nerve synaptic clefts) as shown in Fig. 3A. Representative immunofluorescence images show the TH-positive dopaminergic neurons in the $\mathrm{SN}$ at different magnifications (Fig. 3D; 10X and 63X). Bar graphs show that the expressions of TH (Fig. 3B), DAT (Fig. 3C) densitometry, TH-positive area (Fig. $3 \mathrm{E})$ and the number of $\mathrm{TH}$-positive dopaminergic neurons (Fig. 3F) were significantly reduced in both the WT mice and GMFKO mice when compared with control mice. However, we noticed

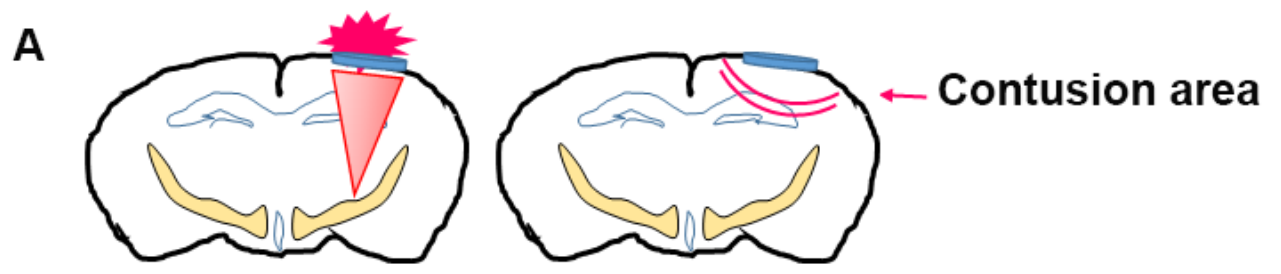

B

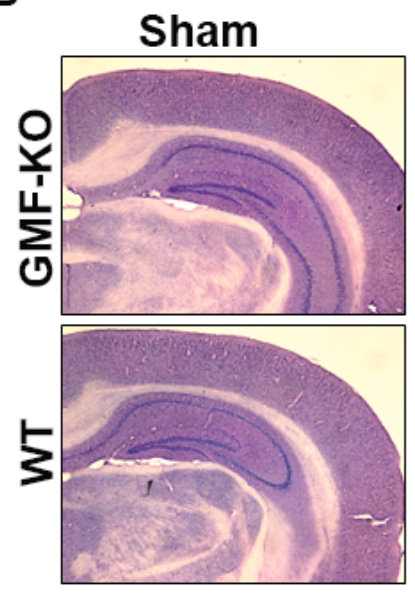

PostTBI-24 h
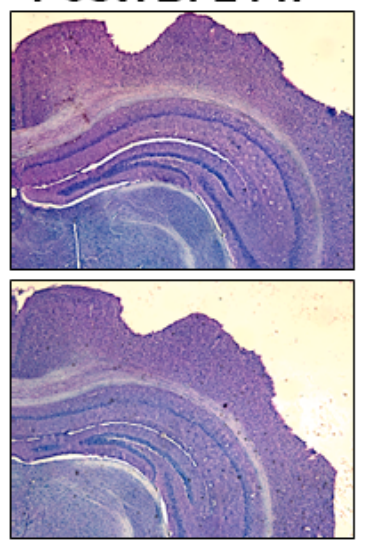

PostTBI-72 h
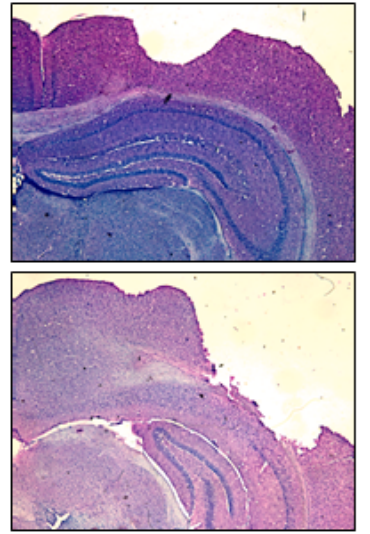

C

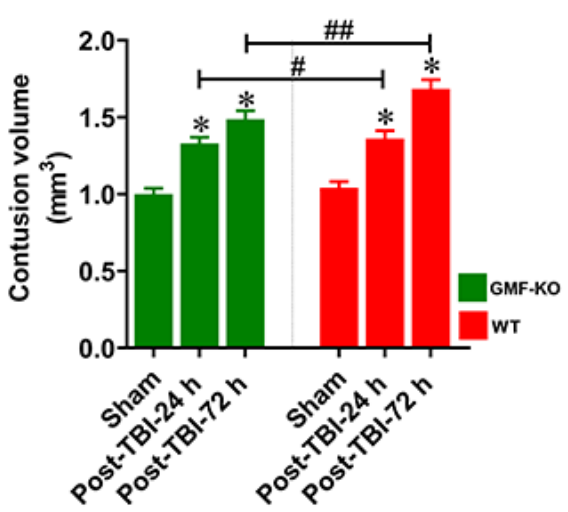

Fig. 2. Absence of GMF reduces TBI induced contusion volume and amplifies brain tissue damage. TBI caused an expanding contusion volume in WT and GMF-KO mice to brain cortical lesions. The illustration of the cortical tissue lesion after weight drop induced TBI (A). Nissl staining showed the temporal pattern of anatomical structure change (B). Bar graphs show the quantification of cortical contusion volume or cavity (C; $\mathrm{n}=6)$. Values are presented as mean \pm SEM $(n=6)$. ${ }^{*} p<0.05$ control vs TBI subjected mice; ${ }^{*} \mathrm{p}<0.05$ and ${ }^{\# *} \mathrm{p}<0.01$ GMF-KO TBI subjected mice vs WT TBI subjected mice. 


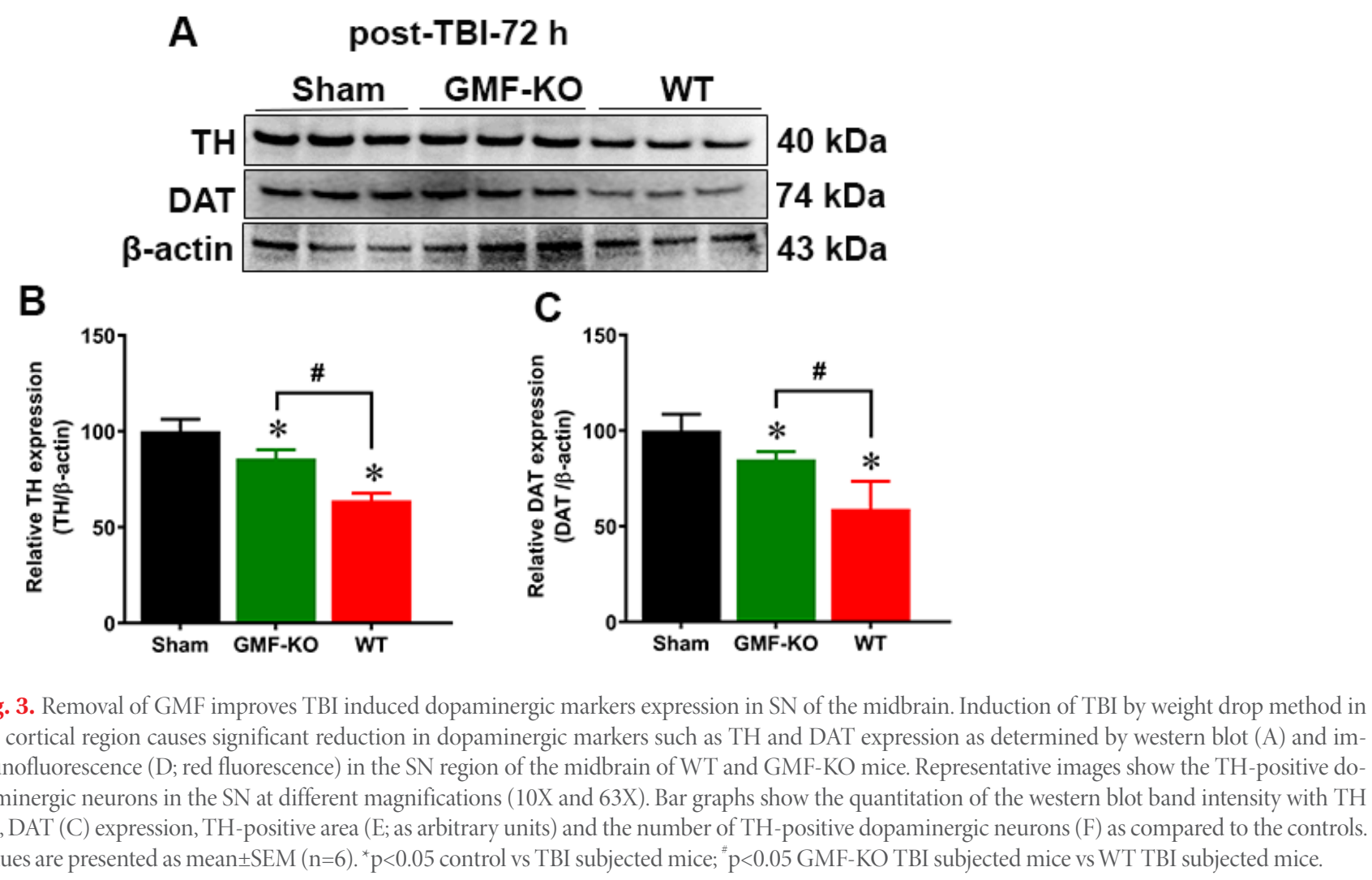

that GMF-KO mice showed a significantly enhanced expression of these proteins when compared with WT TBI subjected mice. No significant reductions were found between the sham-operated controls. Together, these results suggest that GMF aggravates TBI induced dopaminergic neuronal loss as represented by markers $\mathrm{TH}$ and DAT expression in $\mathrm{SN}$ of the midbrain.

\section{GMF amplifies TBI induced UCHL1 and glial activation in SN of midbrain}

To determine the expression of UCHL1 and GFAP, which are promising biomarkers for TBI, we performed western blot on protein homogenates from the $\mathrm{SN}$ of midbrain after $72 \mathrm{~h}$ post-TBI (Fig. 4A). UCHL1 is a thiol protease that helps to recognize and hydrolyze a peptide bond at the C-terminal glycine of ubiquitinated proteins in the brain. GFAP is a filament protein of astroglial skeleton and represents glial injury in the brain. However, the direct relationship between these markers have not been studied in TBI [78]. Results show that UCHL1 expression (Fig. 4B) significantly increased, along with the GFAP expression (Fig. 4C) in the $\mathrm{SN}$ of midbrain after TBI when compared with sham mice. In addition, we found that TBI subjected GMF-KO mice showed significantly lower expressions of UCHL1 and GFAP when compared with WT TBI subjected mice. There are no significant differences in UCHL1 and GFAP expressions observed between the sham-operated controls from WT and GMF-KO mice. Taken together, our results indicate that GMF is involved in the TBI induced UCHL1 expression that may mediate glial injury in SN of midbrain $72 \mathrm{~h}$ post-TBI.

\section{GMF induces NF-kB activation and neuroinflammatory proteins expression in SN of midbrain of TBI subjected mice}

To study the role of GMF in the activation of nuclear factor$\kappa \mathrm{B}(\mathrm{NF}-\mathrm{kB})$ and neuroinflammatory markers expression, we performed western blot on protein lysates from the $\mathrm{SN}$ of the midbrain of $72 \mathrm{~h}$ post-TBI mice (Fig. $5 \mathrm{~A}$ and $5 \mathrm{C}$ ). NF- $\mathrm{kB}$ is a key transcriptional regulator of inflammatory genes. iNOS is pathologically upregulated in the brain after neuronal damage or injury, including TBI. COX-2 is an inducible isoform upregulated by reactive oxygen species (ROS), inflammatory cytokines and mitogens. Results shows a significant enhancement in the phosphorylatedNF-kB (p-NF-kB; Fig. 5B), iNOS (Fig. 5D) and COX2 (Fig. 5E) expression in WT and GMF-KO TBI subjected mice groups as compared with control mice. Furthermore, we found that GMF$\mathrm{KO}$ mice subjected to TBI showed a significant reduction in $\mathrm{p}$ NF-kB, iNOS and COX2 expressions as comparison with WT TBI subjected mice. No significant alterations were found in p-NF-kB 


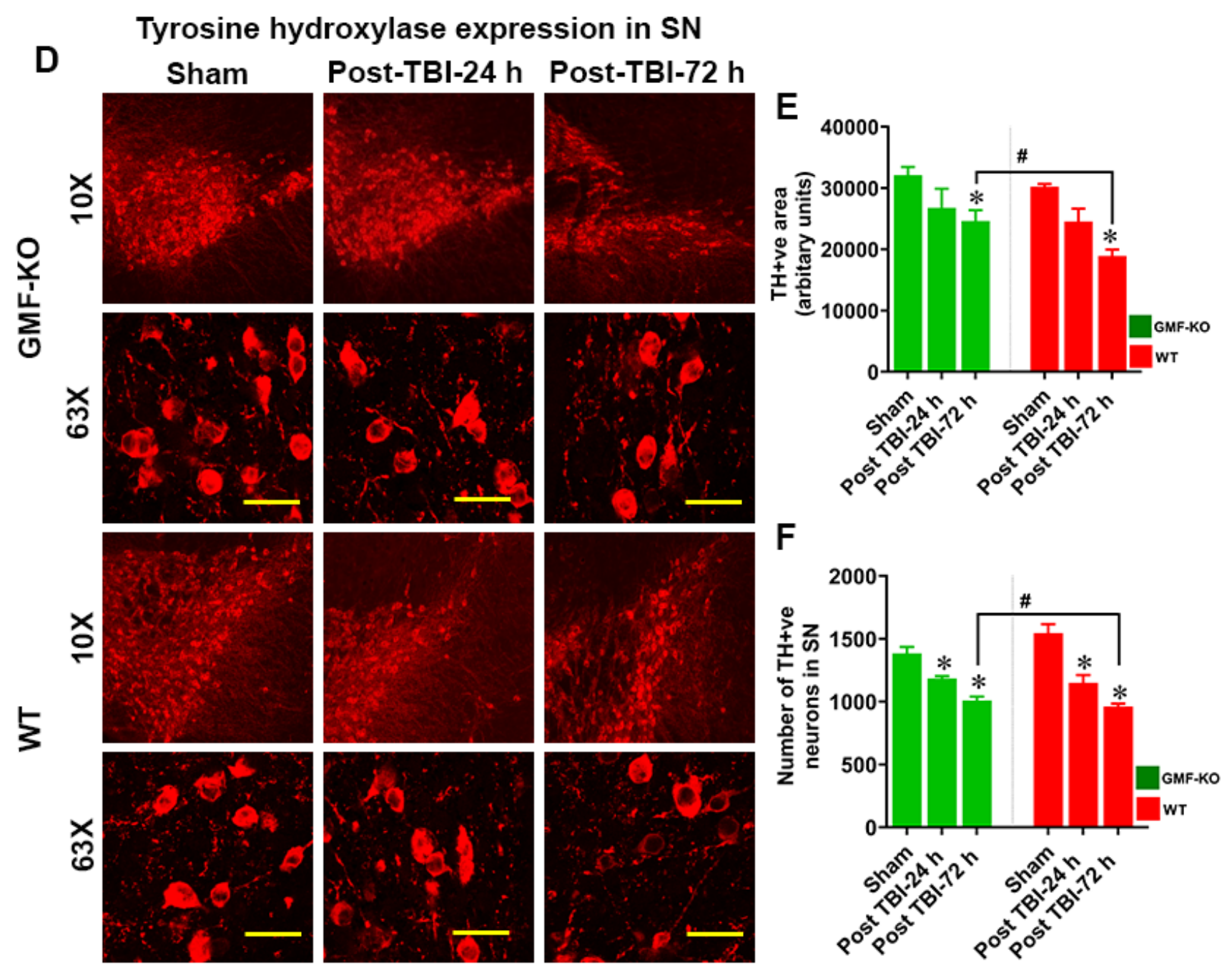

Fig. 3. Continued.

iNOS and COX2 expressions between the sham-operated control mice. These results indicate that GMF is associated with the aggravation of TBI induced neuroinflammation in SN of midbrain $72 \mathrm{~h}$ post-TBI.

\section{GMF attenuates TBI induced expression of neurotrophic} factors in SN of midbrain

We examined the involvement of GMF in the expression of neurotrophic factors such as BDNF and GDNF in mice brain after 72 $\mathrm{h}$ TBI. We analyzed BDNF and GDNF (key neurotrophic proteins, involved with the survival and function of selected populations of brain dopaminergic, serotoninergic, and GABAergic neurons) expression, as shown in Fig. 6A. Bar graphs show that BDNF and GDNF expressions were significantly reduced in both the WT mice and GMF-KO mice when compared with sham mice. However, GMF-KO mice showed significantly increased expressions in
BDNF (Fig. 6B) and GDNF (Fig. 6C) expressions when compared with WT TBI subjected mice. No significant differences between the expressions of these markers were observed in the sham-operated controls from WT and GMF-KO mice. These results indicate that GMF may be involved in the neuronal survival and population after TBI by controlling BDNF and GDNF expression in SN of the midbrain.

Involvement of GMF in TBI induced UCHL1 expression in the neurons and its fiber

We performed double immunofluorescence staining to show that UCHL1 expression was increased in the neuronal cell body (MAP2; Fig. 7A) as well as in the neurofilament region (NFL, Fig. 7D) of TBI subjected mice after $24 \mathrm{~h}$ and $72 \mathrm{~h}$. Representative immunofluorescence images show that MAP2 and NF-L (red fluorescence) expression colocalized with UCHL1 expression (green 


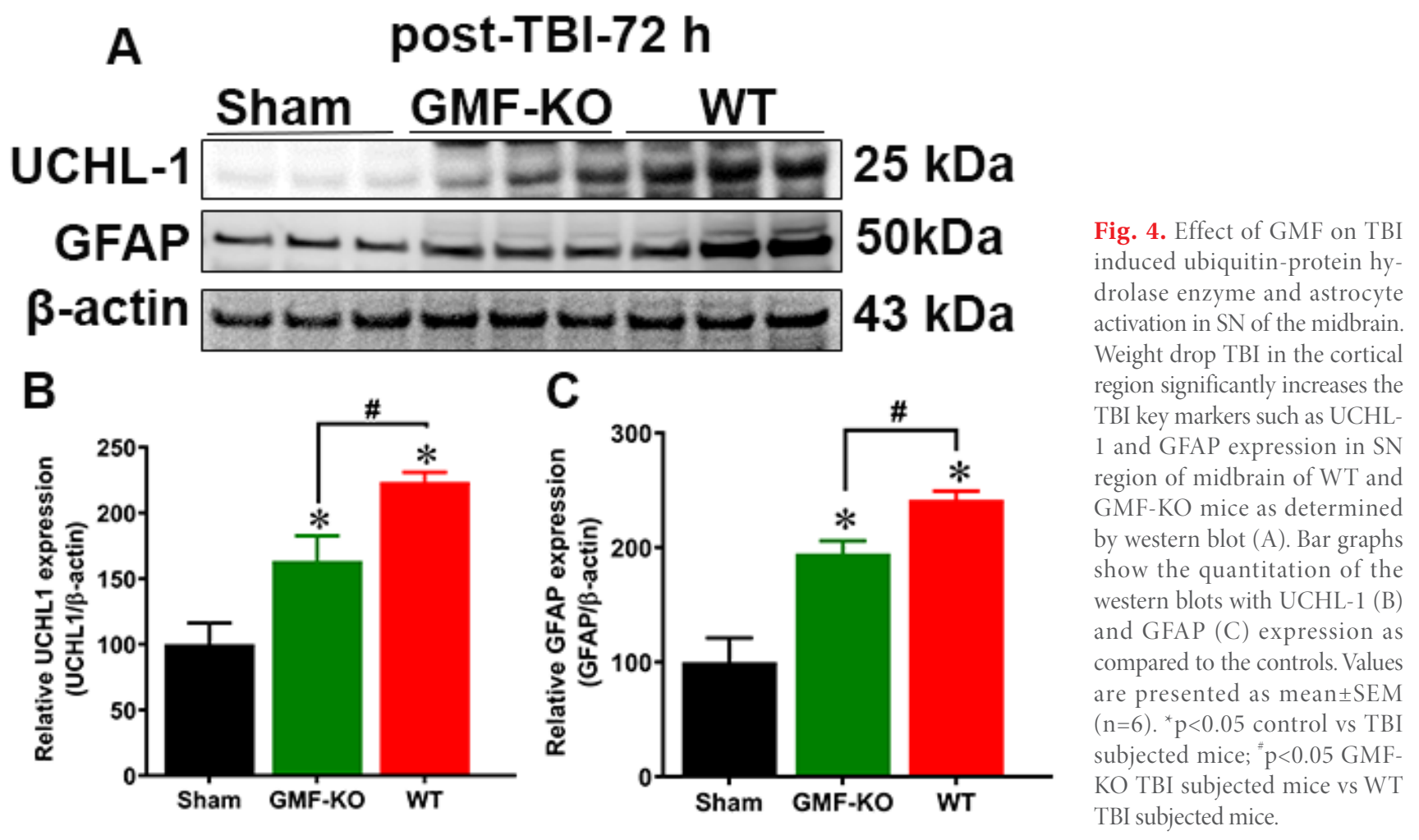

A post-TBI-72 h

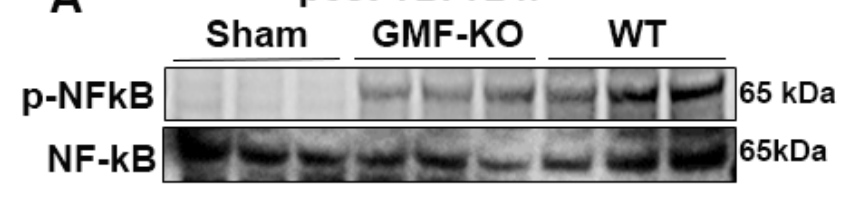

C post-TBI-72 $\mathrm{h}$

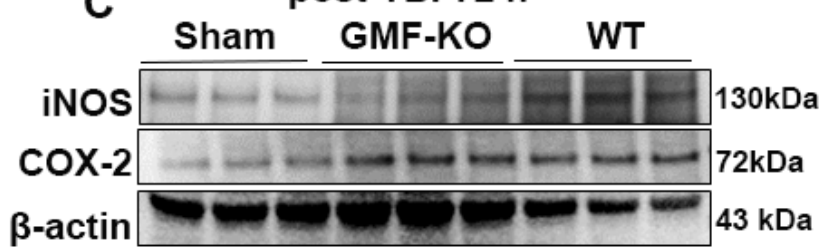

B

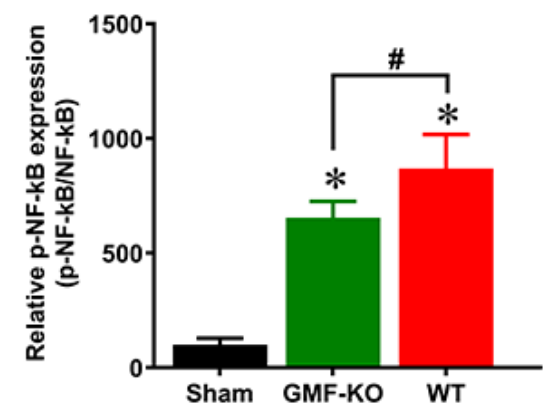

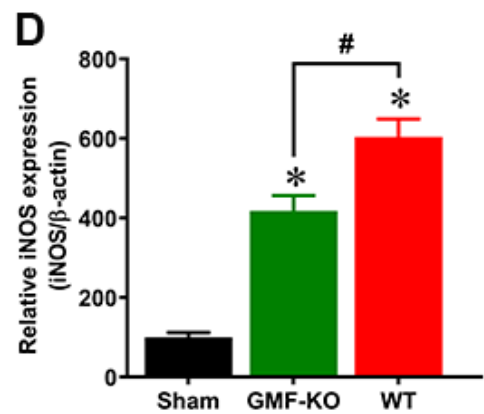

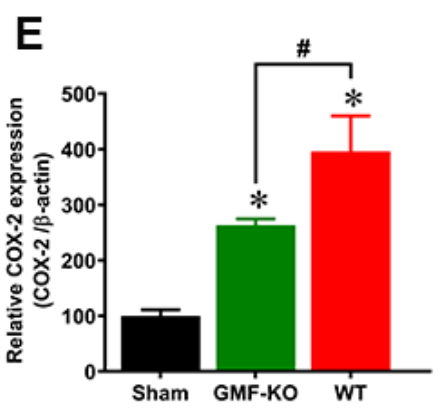

Fig. 5. Deficiency of GMF reduces NF-kB activation and neuroinflammatory proteins expression in SN of midbrain from mice subjected toTBI. Weight drop TBI in the cortical region significantly increases the activation of NF-kB, neuroinflammatory proteins such as iNOS and COX2 expression in SN region of the midbrain of WT and GMF-KO mice as determined by western blot (A and C). Bar graph shows the quantitation of blot intensity (B, D and E) expression as compared to the controls. Values are presented as mean \pm SEM $(n=6) .{ }^{*} p<0.05$ control vs TBI subjected mice; ${ }^{*} p<0.05$ GMF-KO TBI subjected mice vs WT TBI subjected mice.

fluorescence) in the neuronal body (as stained with MAP2, red fluorescence, Fig. 7A) as well as in neurofilament region (as stained with NFL, red fluorescence, Fig. 7D). Bar graphs show the quanti- tation of the total average intensity of MAP2 (Fig. 7B and C), NF-L (Fig. 7E) were significantly reduced meanwhile UCHL-1 (Fig. 7F) expression significantly increased as compared to the sham oper- 


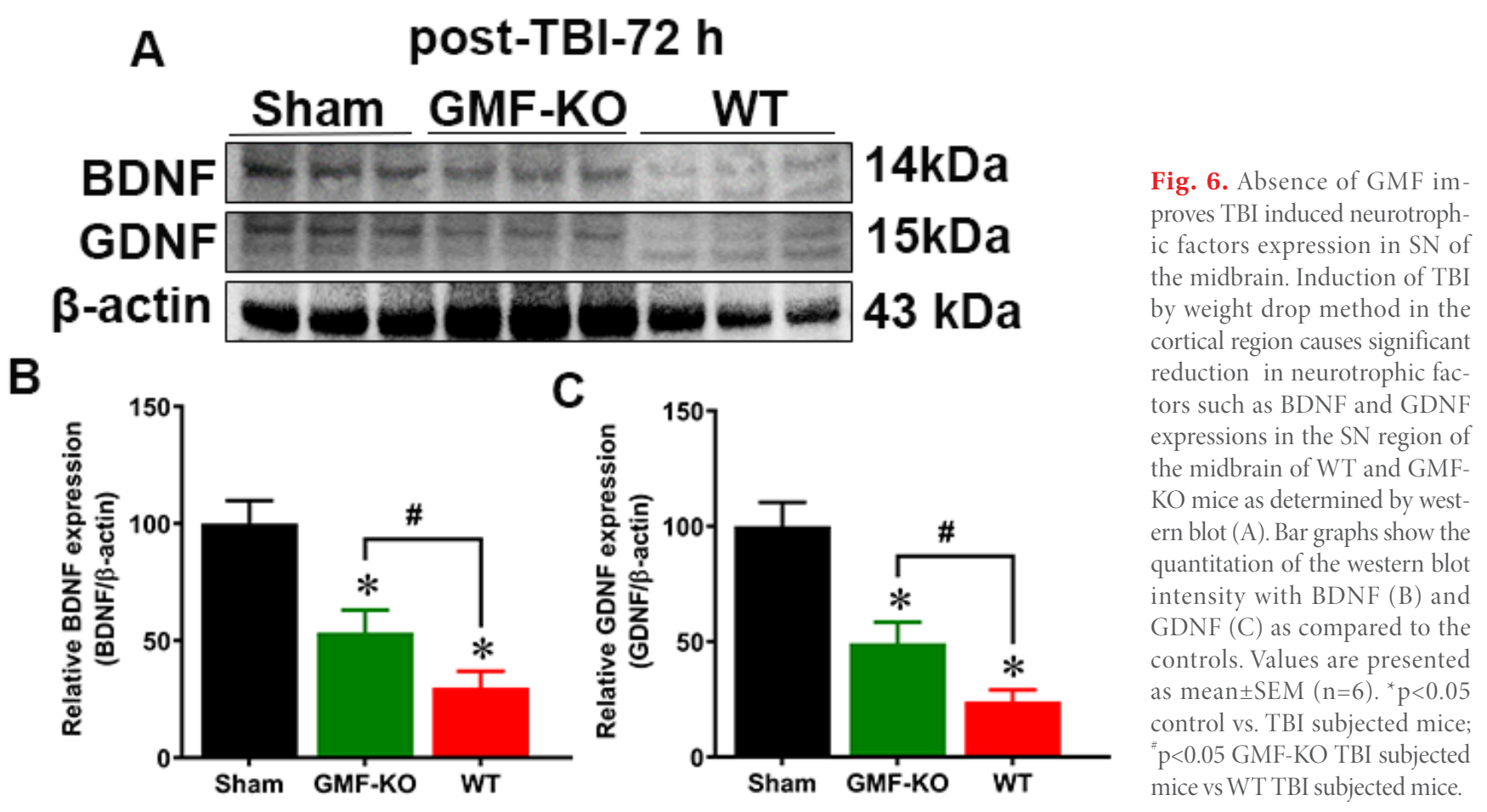

A
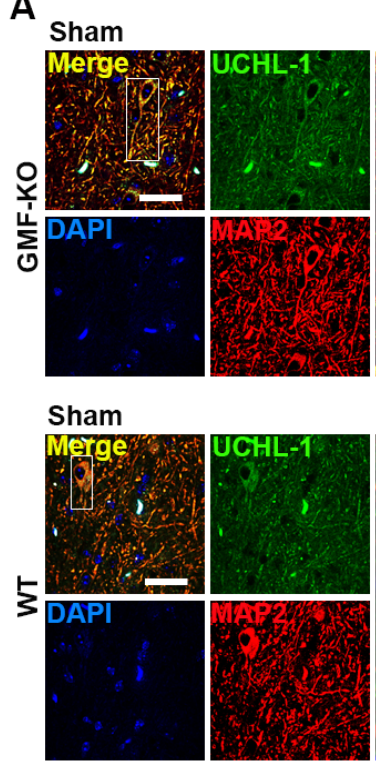
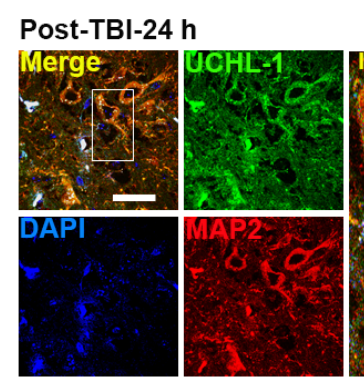

Post-TBI-24 h
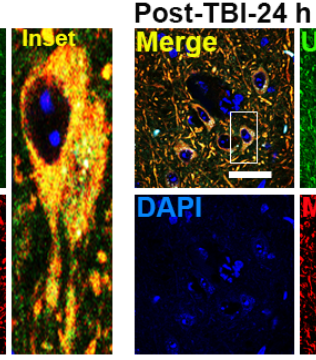
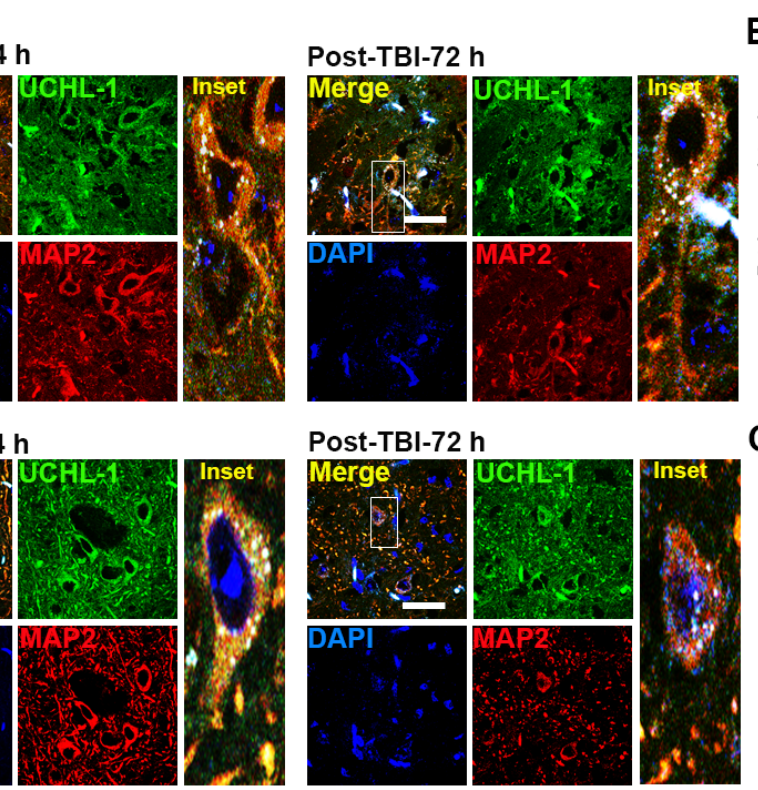

B GMF-Kо

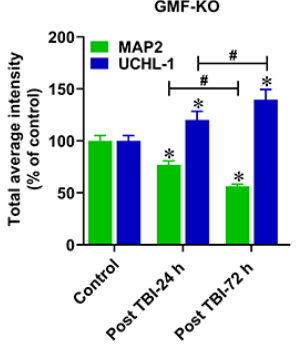

Fig. 7. The involvement of GMF in TBI induced UCHL-1 expression in the neurons and its fiber. Induction of TBI in the cortical region enhances UCHL-1 protein expression in neurons of the midbrain as determined by immunofluorescence. Representative images show a qualitative enhancement of UCHL-1 expression in neurons (A) and its fiber (D) after weight drop induced TBI in mice brain at $24 \mathrm{~h}$ and $72 \mathrm{~h}$ time point. Bar graphs show the quantitation of the total average intensity of MAP2 (B), UCHL1 (C), NF-L (E) colocalized with UCHL-1 (F) as compared to the sham operated controls. Values are presented as mean \pm SEM $(n=6)$ and expressed as percentage of control. ${ }^{*} p<0.05$ control vs. TBI subjected mice; ${ }^{*} p<0.05$ GMF-KO TBI subjected mice vs WT TBI subjected mice. Scale bar $25 \mu \mathrm{m}$.

ated controls. However, this increase in UCHL1 expression was significantly lower in the GMF-KO TBI- subjected mice compared with WT TBI- subjected mice. No significant differences were found between the sham-operated controls from WT and GMFKO mice. These immunofluorescence results imply that GMF a neuroinflammatory protein may be involved in the UCHL1 ex- 

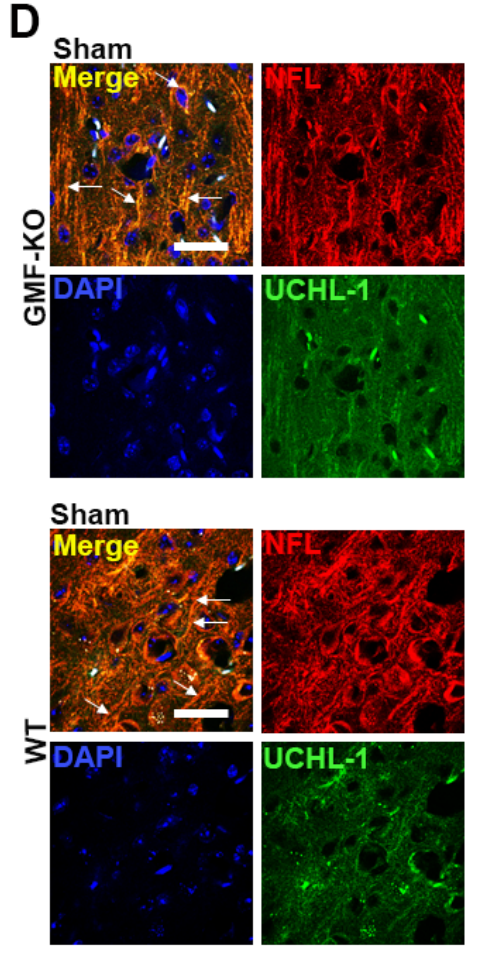
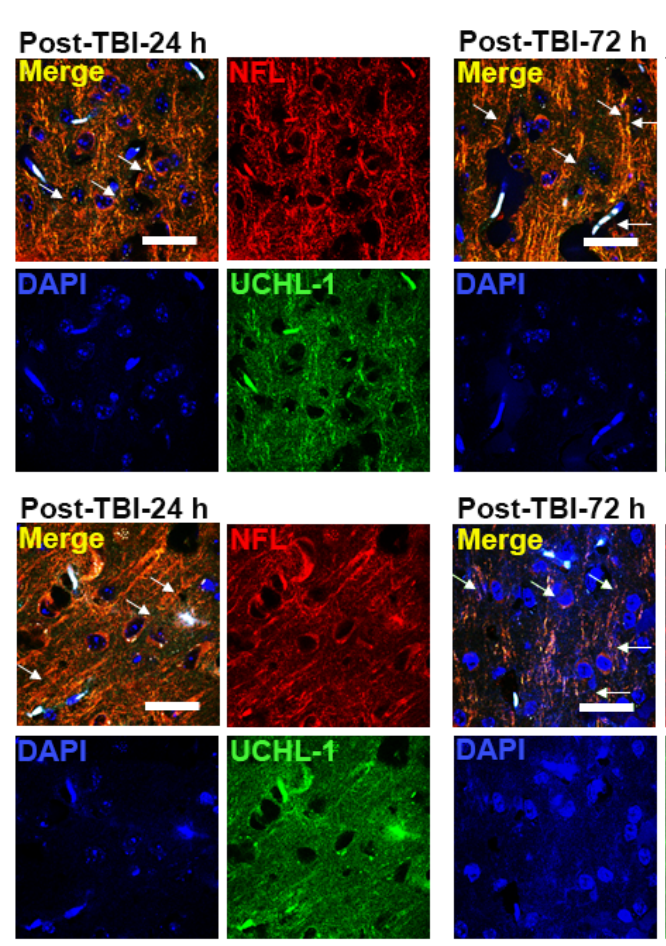
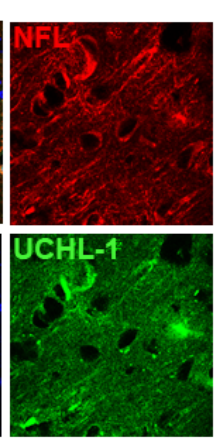

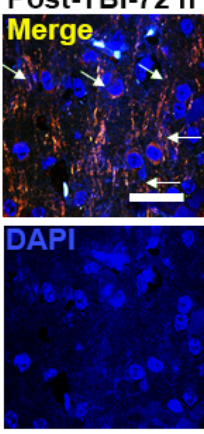

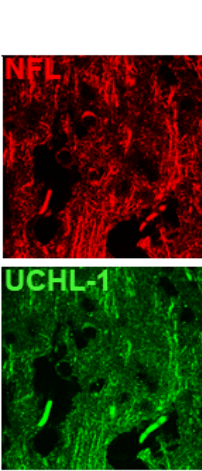
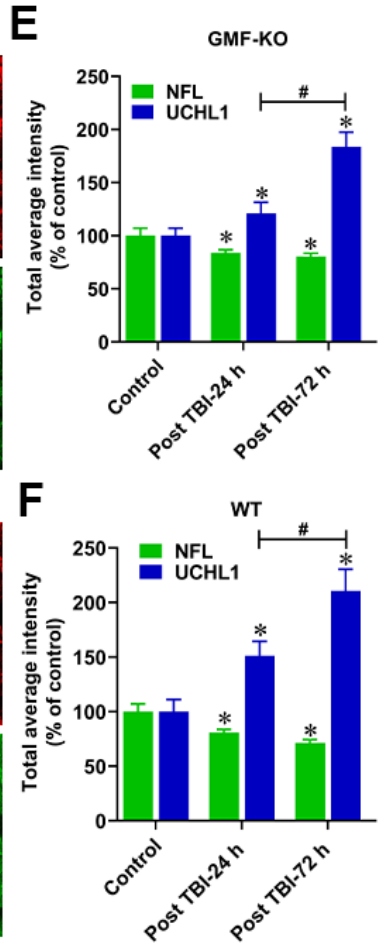

Fig. 7. Continued.

pression in neurons during the TBI induced neuroinflammation in the brain.

\section{GMF influences the TBI induced axonal injury in dopami- nergic neurons of the midbrain}

To determine the involvement of axonal injury of dopaminergic neurons after traumatic brain injury we performed immunofluorescence and axonal measurement as shown in Fig. 8. Results show that weight induced TBI significantly increases the axonal injury when compared with control mice (red fluorescence; Fig. 8A, B and C). However, we noticed that GMF-KO TBI- subjected mice show significant preservation in the axonal injury of TH positive neurons as compared with WT TBI subjected mice. No significant differences were found between the sham-operated controls from WT and GMF-KO mice.

\section{GMF affects TBI induced UCHL1 expression and TH posi- tive dopaminergic neurons of the median eminence}

We further performed double immunofluorescence staining to show the TH positive cells in the median eminence after WT mice and GMF-KO mice were subjected to TBI (Fig. 9). Representative images show that TH positive (red fluorescence) and UCHL1 expressions (green fluorescence) in WT and GMF-KO mice subjected to TBI (Fig. 9A). Bar graphs show the number of TH-Positive tanycytes were significantly higher in the median eminence after TBI of GMF-KO TBI subjected mice as compared with WT TBI subjected mice (Fig. 9B). However, we found that GMF-KO TBIsubjected mice showed a significantly lowered reduction in $\mathrm{TH}$ positive and UCHL1 expressions as compared with WT TBIsubjected mice. No significant differences were found between the sham-operated controls from WT and GMF-KO mice. These immunofluorescence results specify that GMF, a neuroinflammatory protein may be involved in the capillary plexus in the median eminence of TBI subjected mice brain.

\section{DISCUSSION}

In the present study, we demonstrate the sequence of events along with a strong association of GMF within the TBI pathology to expand secondary consequences that lead to dopaminergic neuronal loss in the SN of the midbrain, which further leads to motor deficits in mice. The salient finding of this study includes a significant reduction in the expression of dopaminergic markers such as TH and DAT after TBI. In addition, the weight drop model induced TBI causes UCHL1 dysfunction and activates NF$\mathrm{kB}$ that drives iNOS and COX-2 to further reductions in GDNF and BDNF expressions that ultimately result in decline of motor behavior in mice. Furthermore, TBI affects TH and UCHL1 ex- 
A Tyrosine hydroxylase expression in $\mathrm{SN} \quad \mathrm{C}$
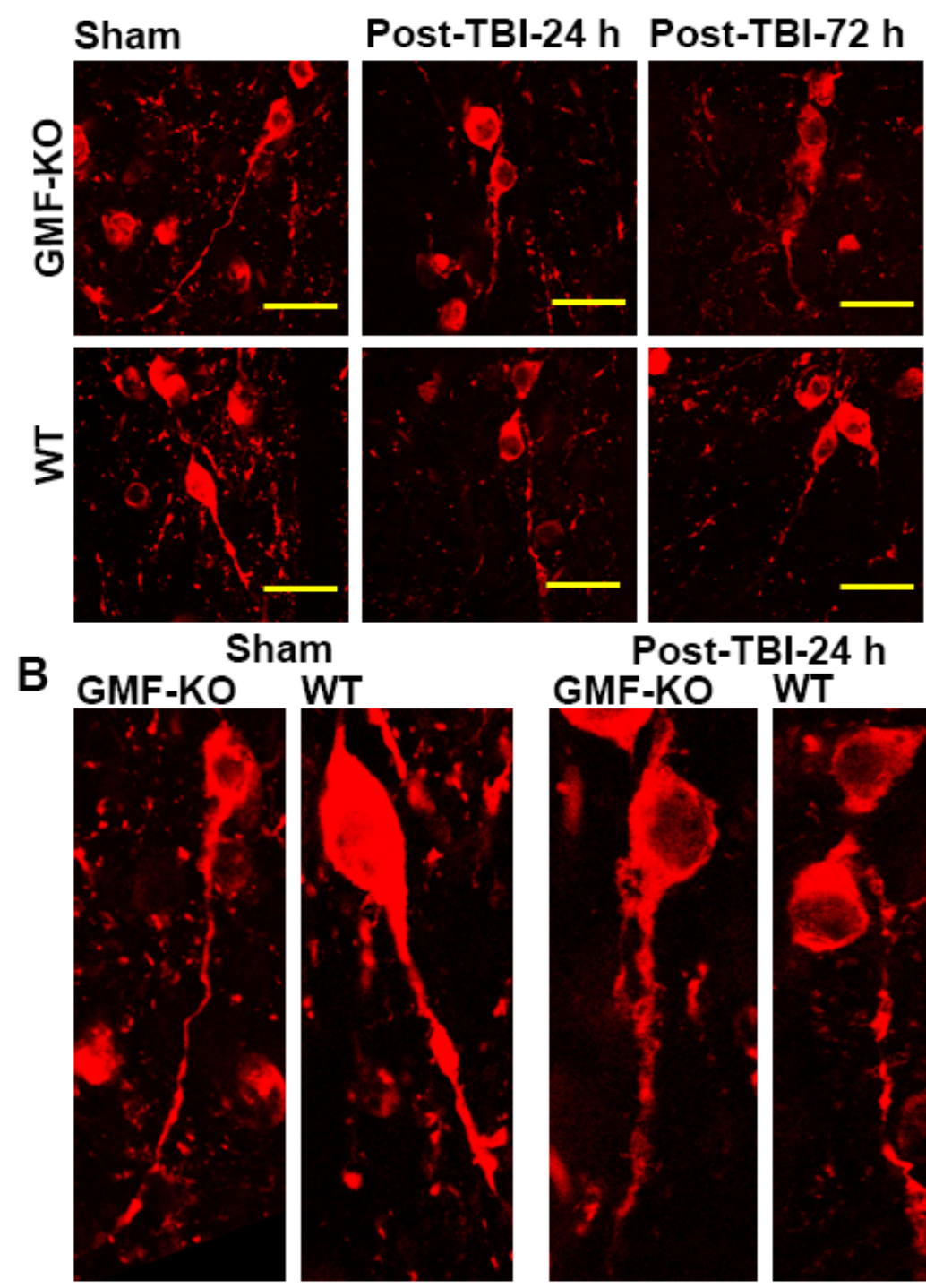

Sham
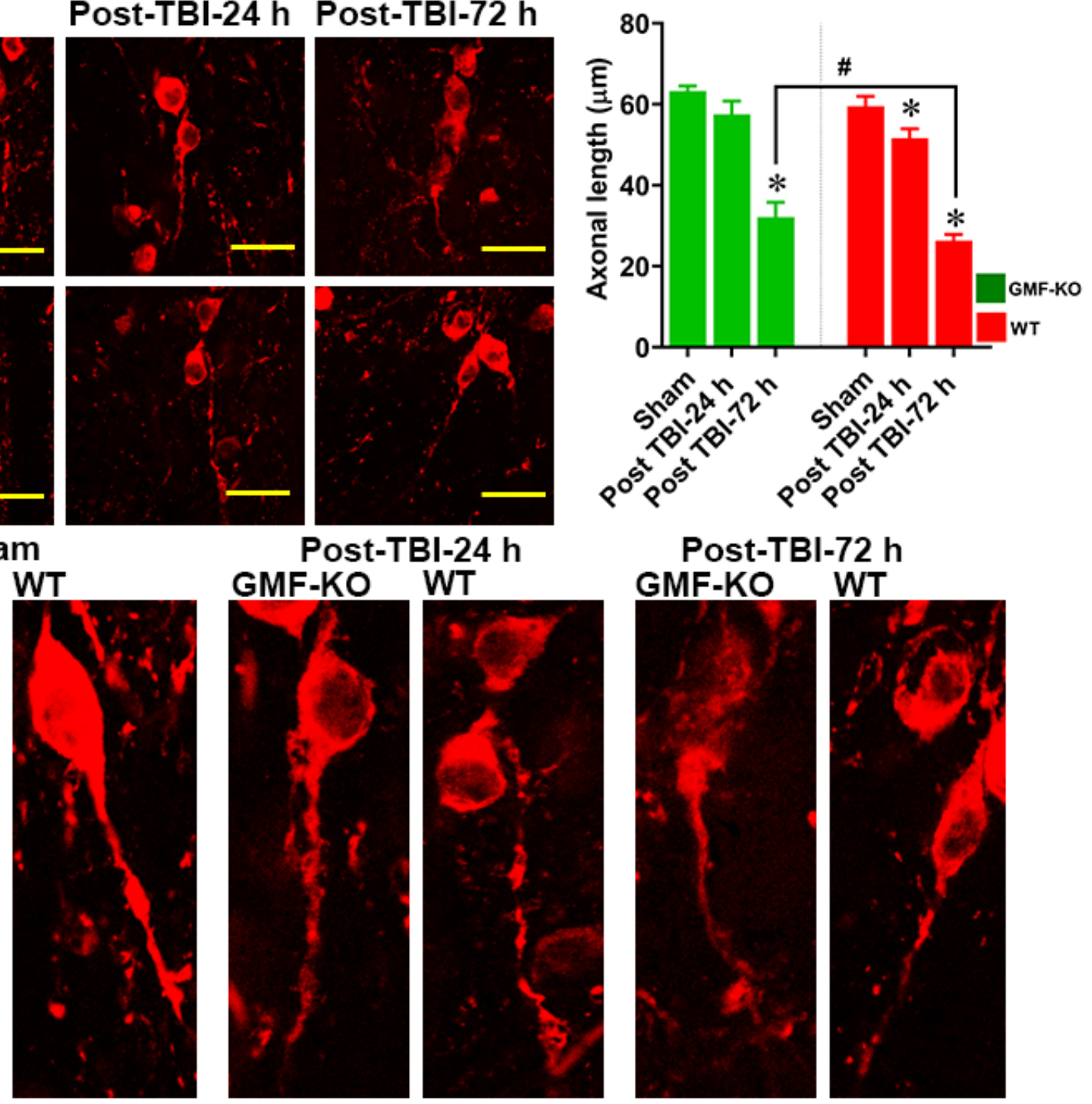

Fig. 8. GMF is involved in TBI induced axonal injury in dopaminergic neurons of the midbrain. TBI-induced cortical brain tissue damage causes significant axonal injury of the TH-positive dopaminergic neurons in the SN region of the midbrain of WT and GMF-KO mice as determined by immunofluorescence (A; Insets B). Bar graph shows the measured axonal length of TH-positive dopaminergic neurons in the field (C), as compared to the controls. Values are presented as mean \pm SEM $(n=6)$. ${ }^{*}<<0.05$ control vs TBI subjected mice; ${ }^{*} \mathrm{p}<0.05$ GMF-KO TBI subjected mice vs WT TBI subjected mice.

pression in median eminence that may causally be linked to neuroendocrine dysfunction in TBI lesioned mice brain.

Globally, TBI is a form of acquired brain injury that causes death and disability, with variable behavioral impairments in survivors. Earlier reports showed that generally, TBI has been examined and viewed as producing a static neurological insult [79]. However, accumulating evidence suggests that TBI can trigger severe secondary insults, including progressive neurodegeneration that induces dementia, cognitive impairments such as loss of memory, processing speed problems, and executive dysfunctions $[79,80]$ as shown in PD [81, 82]. Experimental models of TBI that validate and demonstrate the principal pathological processes associated to PD have been a significant advancement in this field [29, 83]. Furthermore, some TBI survivors experienced cognitive impairments after injury, due to dementia [84]. Previously, it was reported that neuromotor impairments is a common phenomenon in TBI [85]. However, a recent study demonstrates that individuals sustaining a single mTBI suffered long-term cognitive behavioral disability 
A
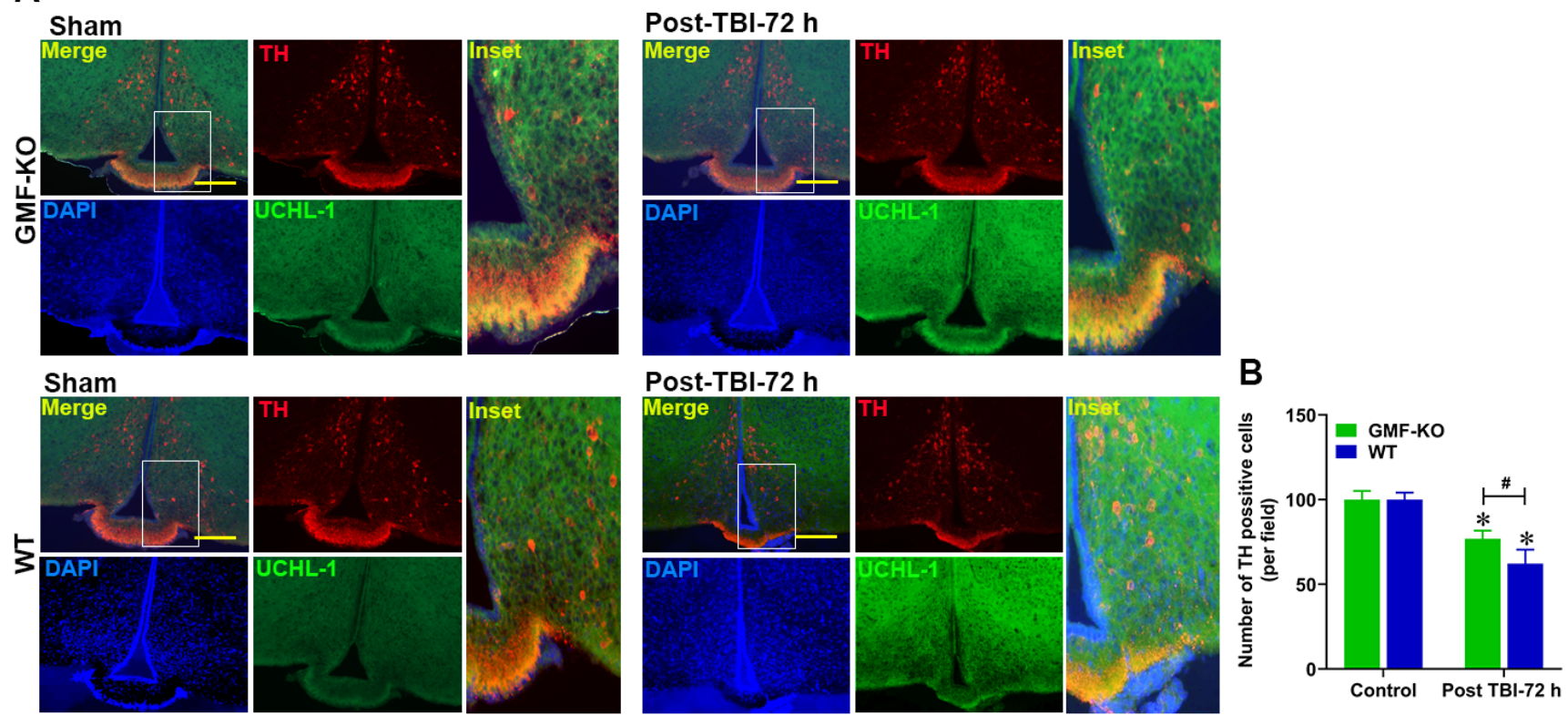

Fig. 9. GMF influences the TBI induced UCHL1 and TH positive dopaminergic neurons expressions in the median eminence. Induction of TBI in the cortical region enhances UCHL-1 protein expression and reduces TH-positive tanycytes expression in the median eminence as determined by immunofluorescence. Representative images show a qualitative enhancement of UCHL-1 expression and reduced TH-positive tanycytes in the median eminence after weight drop induced TBI in mice brain at $72 \mathrm{~h}$ time point (A). Bar graphs show the number of TH-Positive tanycytes in the median eminence after TBI of WT and GMF-KO mice (B). Scale bar $50 \mu \mathrm{m}$. ${ }^{*} \mathrm{p}<0.05$ control vs TBI subjected mice; ${ }^{*} \mathrm{p}<0.05$ GMF-KO TBI subjected mice vs WT TBI subjected mice.

[86] indicating that $>50 \%$ of the population with mTBI progress to secondary insults that is associated with neurodegeneration and motor complications. Previous reports showed that $94 \%$ of people recover after 3 months post-TBI; however, the recovery of independent walking after TBI takes on an average 1.5 months [87]. In a group of severe TBI subjects, about $60 \%$ to $65 \%$ people were incapable of performing locomotor activities such as hopping, jumping, and running [88]. In mouse models, TBI mice exhibit decreased motor and cognitive behavior outcomes compared with control mice [89-93]. Previously it was reported that the functional recovery rate depends upon the type (mild, moderate and severe), mechanism of injury and the specific region of injury in the brain [94]. However, measures of fine motor control fail to identify deficits with mild TBI, even when participants are tested within the first 10 days postinjury. Furthermore, longer term follow-up of these findings has not been reported, though in adults, motor findings have been identified years after mild TBI [95]. However, substantial spontaneous recovery occurs in the weeks to months following TBI. In addition, the functional and cognitive outcomes during early intensive neurorehabilitation compared to the potential recovery patterns of patients presenting with cognitive motor dissociation (CMD) shows more disorders of consciousness (DOC) and non-DOC, but not the functional outcome [96].
However. understanding how the remaining motor and sensory cordination can support the recovery of such functions has been a primary goal of recent neuroscientific research. Currently we are focusing on the chronic (upto 30 days post-TBI) model of TBI to elucidate the functional recovery of WT and GMF-KO mice that will answer the recovery phase and chronic pathological changes that are associated with and without GMF in mice.

Our present findings show that the absence of GMF significantly prevents TH and DAT expression leading to improvement in motor behavioral performance in mice $[60,61,97]$. The present study shows that balance, coordination and neuro muscular strength are significantly reduced and the increased immobility time may be due to reduced expression of TH and DAT in WT mice subjected to weight drop induced TBI. However, GMF-KO mice subjected to TBI show a significant improvement of these behavioral performances compared with WT mice.

Both UCHL1 and GFAP showed promise as biomarkers after brain injury, especially in TBI. GFAP is an intermediate filament skeletal protein of astrocytes [98] and its levels could be indicative of glial cell injury [99]. Neuronal UCHL1 is involved in either adding or removing ubiquitin from the intracellular proteins and increase in its levels signifies neuronal injury [100-102]. Increased $\mathrm{UCH}-\mathrm{L} 1$ concentrations and GFAP expression in TBI have been 
linked to injury severity and worse outcome after TBI. Increased GFAP expression has been correlated with axonal injury, elevated intracranial pressure, and mortality $[78,103-107]$ and has outperformed S-100 $\beta$ in detecting intracranial injuries on patients with extracranial injuries $[104,108]$. Our earlier findings indicated that the absence of GMF in mice (GMF-KO mice) significantly reduced GFAP expression when compared with WT mice $[60,61$, 97]. In the present study, we show that UCHL1 and GFAP expressions were significantly increased in WT and GMF-KO mice subjected to TBI when compared with controls. However, we found that GMF-KO mice showed less expression of these proteins compared with WT TBI mice.

$\mathrm{NF}-\kappa \mathrm{B}$ is a crucial transcriptional regulator of inflammation that is involved in the cellular processes such as apoptosis, neuronal cell survival and damage. The activation and translocation of NF$\kappa B$ may persist in TBI and it has been shown that NF- $\kappa B$ plays a key role in the inflammatory processes in neurotrauma [19]. Our data also shows an increased expression of NF- $\kappa B$ after $72 \mathrm{~h}$ TBI. Furthermore, midbrain NF- $\mathrm{B}$ activation was accompanied with transcriptional increases in inflammatory markers COX2 and iNOS. COX-2 production in turn leads to high levels of neurotoxic $\mathrm{NO}$ and superoxide radicals. COX-2, a major source to generate prostaglandins, is represented as a potential risk factor for degeneration of dopaminergic neurons. Previous reports showed that increased COX-2 expression was localized to dopaminergic neurons of the SN in the post-mortem brains of PD patients [109]. Here, we hypothesize that activation and translocation of NF- $\mathrm{\kappa B}$ in the midbrain could play a crucial role in determining dopaminergic neuronal fate through COX-2 and iNOS. This activation may contribute to the neuroinflammatory processes in the nigrostriatal pathway, which influences the neurodegeneration.

GDNF is an essential factor, that influences the survival of dopaminergic neurons in the $\mathrm{SN}$ of midbrain by increasing synaptic excitability [110] and decreasing neuronal loss [111]. BDNF, NT-3, and GDNF increase dopamine uptake by binding to high affinity receptors to stimulate survival and morphological differentiation of nigral dopaminergic neurons [112-115]. Impellizzeri et al. [116] reported a significant reduction of neurotrophic factors expression such as BDNF, GDNF, and NT-3 in the midbrain region after TBI insult. This is the first report where we are showing the involvement of GMF in the association of TBI related pathological progression towards PD- like pathology. We found that reduced expression of TH, DAT, BDNF and GDNF is associated with increased expression of UCHL1, GFAP, p-NF-kB, iNOS and COX2 expresion. In the present study, we found that weight drop induced TBI significantly decreased the expression of BDNF and GDNF compared to control mice. In addition, the absence of GMF in mice subjected to TBI showed a significant improvement in the expression of these trophic factors, indicating that GMF may be involved in the inhibition of neurotrophic factors expression in the midbrain region. Since, median eminence contains a number of neurondocrine nerve endings [117]; accordingly, endocrine dysfunctions are known consequences of TBI in patients, and endocrine axes remain impaired when assayed up to 5 years after TBI $[118,119]$. Previously, it has been reported that dysfunction of neuroendocrine system enhances the outcome of secondary complications after TBI that causes severe neuropsychiatric symptoms and negatively regulates the quality of behavioral outcomes even after recovery from TBI $[117,120]$. However, accumulating evidence suggest that dysfunctions of tanycytes in median eminence plays an important role in the etiology of motor dysfunction, impairments in concentration, depression, anxiety, fatigue, and loss of facial expression due to the astroglial activation upon TBI [117, 121]. In this study, we found that WT TBI subjected mice show significantly less number of TH-positive tanycytes in the median eminence when compared with GMF-KO mice. Reduced number of TH-positive tanycytes may reduce the axonal transportation between the median eminence and nigrostriatal pathway leading to motor behavioral impairments in the TBI subjected mice as we have shown in this study.

In conclusion, our present findings render insights into the possible pathophysiological regulatory mechanism of GMF action in the weight drop induced TBI that induces motor deficits in mice. We demonstrate that GMF may serve as the pathological factor amd a link between TBI and the development of PD-like pathology. Our data indicate that TBI induces altered expression of dopaminergic markers such as TH and DAT in neurons, and it may be upregulated by GMF in the $\mathrm{SN}$, providing neurodegenerative pathology in TBI. In addition, upregulated expression of UCHL1 and GFAP indicate the severity of TBI that leads to activation of sequential neuroinflammatory responses via NF-kB mediated iNOS and COX-2 expression. Furthermore, reduction in expression of neurotrophic factors such as BDNF and GDNF leads to neurofilament loss along with UCHL1 expression. Ultimately these changes in the midbrain lead to motor behavioral impairments. The global knockdown of GMF significantly reduced these pathological changes in mice after $72 \mathrm{~h}$ TBI. These findings warrant further therapeutic relevance of the aberrant expression of GMF as a potential predictive biomarker for the progressive secondary insults post TBI that is mediated by neuroinflammation and may enhance potential neurodegeneration (with PD-like pathology) in TBI. Furthermore, GMF may serve as a key regulatory factor between the TBI and associated PD symptoms which opens up new therapeutic avenues. 


\section{ACKNOWLEDGEMENTS}

Research was sponsored by the Leonard Wood Institute in cooperation with the U.S. Army Research Laboratory and was accomplished under Cooperative Agreement Number W911NF-14-2-0034. The views and conclusions contained in this document are those of the authors and should not be interpreted as representing the official policies, either expressed or implied, of the Leonard Wood Institute, the Army Research Laboratory or the U.S. Government. The U.S. Government is authorized to reproduce and distribute reprints for Government purposes notwithstanding any copyright notation heron. The authors express their gratitude for the Acute Effects of Neurotrauma Consortium in assisting and coordinating the conduct of this project at Fort Leonard Wood. Dr Zaheer (AZ) is the recipient of the VA Research Career Scientist Award.

\section{ETHICS STATEMENT}

The animal study was reviewed and approved by The University of Missouri animal care facility, and they were used in accordance with the guidelines approved by the IACUC and National Institutes of Health, Unites States of America.

\section{REFERENCES}

1. Menon DK, Schwab K, Wright DW, Maas AI; Demographics and Clinical Assessment Working Group of the International and Interagency Initiative toward Common Data Elements for Research on Traumatic Brain Injury and Psychological Health (2010) Position statement: definition of traumatic brain injury. Arch Phys Med Rehabil 91:1637-1640.

2. Taylor CA, Bell JM, Breiding MJ, Xu L (2017) Traumatic brain injury-related emergency department visits, hospitalizations, and deaths - United States, 2007 and 2013. MMWR Surveill Summ 66:1-16.

3. Faul M, Xu L, Wald MM, Coronado V, Dellinger AM (2010) Traumatic brain injury in the United States: national estimates of prevalence and incidence, 2002-2006. Inj Prev 16(Suppl 1):A268.

4. Skolnick BE, Maas AI, Narayan RK, van der Hoop RG, MacAllister T, Ward JD, Nelson NR, Stocchetti N; SYNAPSE Trial Investigators (2014) A clinical trial of progesterone for severe traumatic brain injury. N Engl J Med 371:2467-2476.

5. Coronado VG, McGuire LC, Sarmiento K, Bell J, Lionbarger MR, Jones CD, Geller AI, Khoury N, Xu L (2012) Trends in traumatic brain injury in the U.S. and the public health re- sponse: 1995-2009. J Safety Res 43:299-307.

6. Maas AIR, Menon DK, Adelson PD, Andelic N, Bell MJ, Belli A, Bragge P, Brazinova A, Büki A, Chesnut RM, Citerio G, Coburn M, Cooper DJ, Crowder AT, Czeiter E, Czosnyka M, Diaz-Arrastia R, Dreier JP, Duhaime AC, Ercole A, van Essen TA, Feigin VL, Gao G, Giacino J, Gonzalez-Lara LE, Gruen RL, Gupta D, Hartings JA, Hill S, Jiang JY, Ketharanathan N, Kompanje EJO, Lanyon L, Laureys S, Lecky F, Levin H, Lingsma HF, Maegele M, Majdan M, Manley G, Marsteller J, Mascia L, McFadyen C, Mondello S, Newcombe V, Palotie A, Parizel PM, Peul W, Piercy J, Polinder S, Puybasset L, Rasmussen TE, Rossaint R, Smielewski P, Söderberg J, Stanworth SJ, Stein MB, von Steinbüchel N, Stewart W, Steyerberg EW, Stocchetti N, Synnot A, Te Ao B, Tenovuo O, Theadom A, Tibboel D, Videtta W, Wang KKW, Williams WH, Wilson L, Yaffe K; InTBIR Participants and Investigators (2017) Traumatic brain injury: integrated approaches to improve prevention, clinical care, and research. Lancet Neurol 16:987-1048.

7. McMillan TM, Teasdale GM, Weir CJ, Stewart E (2011) Death after head injury: the 13 year outcome of a case control study. J Neurol Neurosurg Psychiatry 82:931-935.

8. Maas AI, Stocchetti N, Bullock R (2008) Moderate and severe traumatic brain injury in adults. Lancet Neurol 7:728-741.

9. McKee AC, Robinson ME (2014) Military-related traumatic brain injury and neurodegeneration. Alzheimers Dement 10(3 Suppl):S242-S253.

10. Bruns J Jr, Hauser WA (2003) The epidemiology of traumatic brain injury: a review. Epilepsia 44(s10):2-10.

11. Tagliaferri F, Compagnone C, Korsic M, Servadei F, Kraus J (2006) A systematic review of brain injury epidemiology in Europe. Acta Neurochir (Wien) 148:255-268.

12. Vallée M, McFadyen BJ, Swaine B, Doyon J, Cantin JF, Dumas D (2006) Effects of environmental demands on locomotion after traumatic brain injury. Arch Phys Med Rehabil 87:806813.

13. Kim C, Park JM, Kong T, Lee S, Seo KW, Choi Y, Song YS, Moon J (2018) Double-injected human stem cells enhance rehabilitation in TBI mice via modulation of survival and inflammation. Mol Neurobiol 55:4870-4884.

14. Huang YN, Yang LY, Greig NH, Wang YC, Lai CC, Wang JY (2018) Neuroprotective effects of pifithrin- $\alpha$ against traumatic brain injury in the striatum through suppression of neuroinflammation, oxidative stress, autophagy, and apoptosis. Sci Rep 8:2368.

15. Saatman KE, Duhaime AC, Bullock R, Maas AI, Valadka A, Manley GT; Workshop Scientific Team and Advisory Panel Members (2008) Classification of traumatic brain injury for 
targeted therapies. Version 2. J Neurotrauma 25:719-738.

16. Liu H, Povysheva N, Rose ME, Mi Z, Banton JS, Li W, Chen F, Reay DP, Barrionuevo G, Zhang F, Graham SH (2019) Role of UCHL1 in axonal injury and functional recovery after cerebral ischemia. Proc Natl Acad Sci U S A 116:4643-4650.

17. Okonkwo DO, Yue JK, Puccio AM, Panczykowski DM, Inoue T, McMahon PJ, Sorani MD, Yuh EL, Lingsma HF, Maas AI, Valadka AB, Manley GT; Transforming Research and Clinical Knowledge in Traumatic Brain Injury (TRACK-TBI) Investigators (2013) GFAP-BDP as an acute diagnostic marker in traumatic brain injury: results from the prospective transforming research and clinical knowledge in traumatic brain injury study. J Neurotrauma 30:1490-1497.

18. Mettang M, Reichel SN, Lattke M, Palmer A, Abaei A, Rasche V, Huber-Lang M, Baumann B, Wirth T (2018) IKK2/NF$\kappa \mathrm{B}$ signaling protects neurons after traumatic brain injury. FASEB J 32:1916-1932.

19. Nonaka M, Chen XH, Pierce JE, Leoni MJ, McIntosh TK, Wolf JA, Smith DH (1999) Prolonged activation of NF-kap$\mathrm{paB}$ following traumatic brain injury in rats. J Neurotrauma 16:1023-1034.

20. Zhang H, Zhang D, Li H, Yan H, Zhang Z, Zhou C, Chen Q, Ye Z, Hang C (2018) Biphasic activation of nuclear factor- $\kappa \mathrm{B}$ and expression of p65 and c-Rel following traumatic neuronal injury. Int J Mol Med 41:3203-3210.

21. Jayakumar AR, Tong XY, Ruiz-Cordero R, Bregy A, Bethea JR, Bramlett HM, Norenberg MD (2014) Activation of NF$\kappa \mathrm{B}$ mediates astrocyte swelling and brain edema in traumatic brain injury. J Neurotrauma 31:1249-1257.

22. Snow WM, Albensi BC (2016) Neuronal gene targets of NF$\kappa \mathrm{B}$ and their dysregulation in Alzheimer's disease. Front Mol Neurosci 9:118.

23. Dresselhaus EC, Meffert MK (2019) Cellular specificity of NF- $\kappa \mathrm{B}$ function in the nervous system. Front Immunol 10:1043.

24. Carter BD, Kaltschmidt C, Kaltschmidt B, Offenhäuser N, Böhm-Matthaei R, Baeuerle PA, Barde YA (1996) Selective activation of NF-kappa B by nerve growth factor through the neurotrophin receptor $\mathrm{p} 75$. Science 272:542-545.

25. Maggirwar SB, Sarmiere PD, Dewhurst S, Freeman RS (1998) Nerve growth factor-dependent activation of NF-kappaB contributes to survival of sympathetic neurons. J Neurosci 18:10356-10365.

26. Mattson MP (2000) Apoptosis in neurodegenerative disorders. Nat Rev Mol Cell Biol 1:120-129.

27. Acosta SA, Tajiri N, Shinozuka K, Ishikawa H, Grimmig B, Diamond DM, Sanberg PR, Bickford PC, Kaneko Y, Borlon- gan CV (2013) Long-term upregulation of inflammation and suppression of cell proliferation in the brain of adult rats exposed to traumatic brain injury using the controlled cortical impact model. PLoS One 8:e53376.

28. Saing T, Dick M, Nelson PT, Kim RC, Cribbs DH, Head E (2012) Frontal cortex neuropathology in dementia pugilistica. J Neurotrauma 29:1054-1070.

29. Xiong Y, Mahmood A, Chopp M (2013) Animal models of traumatic brain injury. Nat Rev Neurosci 14:128-142.

30. Dauer W, Przedborski S (2003) Parkinson's disease: mechanisms and models. Neuron 39:889-909.

31. Chen YH, Huang EY, Kuo TT, Miller J, Chiang YH, Hoffer BJ (2017) Impact of traumatic brain injury on dopaminergic transmission. Cell Transplant 26:1156-1168.

32. Wong C, Anderson DJ, Lee EF, Fairlie WD, Ludlam MJ (2012) Direct visualization of Bcl-2 family protein interactions using live cell fluorescent protein redistribution assays. Cell Death Dis 3:e288.

33. Walker KR, Tesco G (2013) Molecular mechanisms of cognitive dysfunction following traumatic brain injury. Front Aging Neurosci 5:29.

34. Wan OW, Chung KK (2012) The role of alpha-synuclein oligomerization and aggregation in cellular and animal models of Parkinson's disease. PLoS One 7:e38545.

35. Ulusoy A, Di Monte DA (2013) a-Synuclein elevation in human neurodegenerative diseases: experimental, pathogenetic, and therapeutic implications. Mol Neurobiol 47:484-494.

36. Chen MH, Chen PC, Lu CH, Chen HL, Chao YP, Li SH, Chen YW, Lin WC (2017) Plasma DNA mediate autonomic dysfunctions and white matter injuries in patients with Parkinson's disease. Oxid Med Cell Longev 2017:7371403.

37. Jenkins PO, De Simoni S, Bourke NJ, Fleminger J, Scott G, Towey DJ, Svensson W, Khan S, Patel M, Greenwood R, Cole JH, Sharp DJ (2018) Dopaminergic abnormalities following traumatic brain injury. Brain 141:797-810.

38. Hicks RR, Smith DH, Lowenstein DH, Saint Marie R, McIntosh TK (1993) Mild experimental brain injury in the rat induces cognitive deficits associated with regional neuronal loss in the hippocampus. J Neurotrauma 10:405-414.

39. Sanders MJ, Dietrich WD, Green EJ (2001) Behavioral, electrophysiological, and histopathological consequences of mild fluid-percussion injury in the rat. Brain Res 904:141-144.

40. Lighthall JW, Dixon CE, Anderson TE (1989) Experimental models of brain injury. J Neurotrauma 6:83-97.

41. Dietrich WD, Alonso O, Halley M (1994) Early microvascular and neuronal consequences of traumatic brain injury: a light and electron microscopic study in rats. J Neurotrauma 
11:289-301.

42. Baddeley A, Logie R, Bressi S, Della Sala S, Spinnler H (1986) Dementia and working memory. Q J Exp Psychol A 38:603618.

43. Buckley MJ (2005) The role of the perirhinal cortex and hippocampus in learning, memory, and perception. Q J Exp Psychol B 58:246-268.

44. Cohen JD, Servan-Schreiber D (1992) Context, cortex, and dopamine: a connectionist approach to behavior and biology in schizophrenia. Psychol Rev 99:45-77.

45. Bales JW, Kline AE, Wagner AK, Dixon CE (2010) Targeting dopamine in acute traumatic brain injury. Open Drug Discov J 2:119-128.

46. Kaplan R, Zaheer A, Jaye M, Lim R (1991) Molecular cloning and expression of biologically active human glia maturation factor-beta. J Neurochem 57:483-490.

47. Lim R, Miller JF, Zaheer A (1989) Purification and characterization of glia maturation factor beta: a growth regulator for neurons and glia. Proc Natl Acad Sci U S A 86:3901-3905.

48. Zaheer A, Fink BD, Lim R (1993) Expression of glia maturation factor beta mRNA and protein in rat organs and cells. J Neurochem 60:914-920.

49. Lim R, Hicklin DJ, Ryken TC, Miller JF, Bosch EP (1988) Endogenous immunoreactive glia maturation factor-like molecule in cultured rat Schwann cells. Brain Res 468:277-284.

50. Lim R, Zaheer A (2006) Glia maturation factor in brain function. In: Handbook of neurochemistry and molecular neurobiology: neuroactive proteins and peptides. 3rd ed. (Lajtha A, Lim R, eds), pp 203-222. Springer US, Boston.

51. Zaheer A, Haas JT, Reyes C, Mathur SN, Yang B, Lim R (2006) GMF-knockout mice are unable to induce brain-derived neurotrophic factor after exercise. Neurochem Res 31:579584.

52. Thangavel R, Stolmeier D, Yang X, Anantharam P, Zaheer A (2012) Expression of glia maturation factor in neuropathological lesions of Alzheimer's disease. Neuropathol Appl Neurobiol 38:572-581.

53. Zaheer A, Lim R (1997) Protein kinase A (PKA)- and protein kinase C-phosphorylated glia maturation factor promotes the catalytic activity of PKA. J Biol Chem 272:5183-5186.

54. Lim R, Zaheer A, Khosravi H, Freeman JH Jr, Halverson HE, Wemmie JA, Yang B (2004) Impaired motor performance and learning in glia maturation factor-knockout mice. Brain Res 1024:225-232.

55. Zaheer A, Zaheer S, Sahu SK, Knight S, Khosravi H, Mathur SN, Lim R (2007) A novel role of glia maturation factor: induction of granulocyte-macrophage colony-stimulating fac- tor and pro-inflammatory cytokines. J Neurochem 101:364376.

56. Flierl MA, Stahel PF, Beauchamp KM, Morgan SJ, Smith WR, Shohami E (2009) Mouse closed head injury model induced by a weight-drop device. Nat Protoc 4:1328-1337.

57. Shishido H, Ueno M, Sato K, Matsumura M, Toyota Y, Kirino Y, Tamiya T, Kawai N, Kishimoto Y (2019) Traumatic brain injury by weight-drop method causes transient amyloid- $\beta$ deposition and acute cognitive deficits in mice. Behav Neurol 2019:3248519.

58. Milman A, Rosenberg A, Weizman R, Pick CG (2005) Mild traumatic brain injury induces persistent cognitive deficits and behavioral disturbances in mice. J Neurotrauma 22:10031010 .

59. Zohar O, Schreiber S, Getslev V, Schwartz JP, Mullins PG, Pick CG (2003) Closed-head minimal traumatic brain injury produces long-term cognitive deficits in mice. Neuroscience 118:949-955.

60. Khan MM, Zaheer S, Thangavel R, Patel M, Kempuraj D, Zaheer A (2015) Absence of glia maturation factor protects dopaminergic neurons and improves motor behavior in mouse model of parkinsonism. Neurochem Res 40:980-990.

61. Khan MM, Kempuraj D, Thangavel R, Zaheer A (2013) Protection of MPTP-induced neuroinflammation and neurodegeneration by Pycnogenol. Neurochem Int 62:379-388.

62. Can A, Dao DT, Terrillion CE, Piantadosi SC, Bhat S, Gould TD (2012) The tail suspension test. J Vis Exp 59:e3769.

63. Machado DG, Kaster MP, BinfaréRW, Dias M, Santos AR, Pizzolatti MG, Brighente IM, Rodrigues AL (2007) Antidepressant-like effect of the extract from leaves of Schinus molle L. in mice: evidence for the involvement of the monoaminergic system. Prog Neuropsychopharmacol Biol Psychiatry 31:421428.

64. Aartsma-Rus A, van Putten M (2014) Assessing functional performance in the mdx mouse model. J Vis Exp 85:51303.

65. Tillerson JL, Miller GW (2003) Grid performance test to measure behavioral impairment in the MPTP-treated-mouse model of parkinsonism. J Neurosci Methods 123:189-200.

66. Fang J, Zhu Y, Wang H, Cao B, Fei M, Niu W, Zhou Y, Wang X, Li X, Zhou M (2019) Baicalin protects mice brain from apoptosis in traumatic brain injury model through activation of autophagy. Front Neurosci 12:1006.

67. Pilati N, Barker M, Panteleimonitis S, Donga R, Hamann M (2008) A rapid method combining Golgi and Nissl staining to study neuronal morphology and cytoarchitecture. J Histochem Cytochem 56:539-550.

68. Coggeshall RE (1992) A consideration of neural counting 
methods. Trends Neurosci 15:9-13.

69. Ahmed ME, Selvakumar GP, Kempuraj D, Thangavel R, Mentor S, Dubova I, Raikwar SP, Zaheer S, Iyer S, Zaheer A (2019) Synergy in disruption of mitochondrial dynamics by A $\beta$ (142 ) and glia maturation factor (GMF) in SH-SY5Y cells is mediated through alterations in fission and fusion proteins. Mol Neurobiol 56:6964-6975.

70. Selvakumar GP, Ahmed ME, Thangavel R, Kempuraj D, Dubova I, Raikwar SP, Zaheer S, Iyer SS, Zaheer A (2020) A role for glia maturation factor dependent activation of mast cells and microglia in MPTP induced dopamine loss and behavioural deficits in mice. Brain Behav Immun. doi: 10.1016/ j.bbi.2020.01.013.

71. Selvakumar GP, Iyer SS, Kempuraj D, Ahmed ME, Thangavel R, Dubova I, Raikwar SP, Zaheer S, Zaheer A (2019) Molecular association of glia maturation factor with the autophagic machinery in rat dopaminergic neurons: a role for endoplasmic reticulum stress and MAPK activation. Mol Neurobiol 56:3865-3881.

72. Selvakumar GP, Janakiraman U, Essa MM, Justin Thenmozhi A, Manivasagam T (2014) Escin attenuates behavioral impairments, oxidative stress and inflammation in a chronic MPTP/probenecid mouse model of Parkinson's disease. Brain Res 1585:23-36.

73. Crocker SJ, Smith PD, Jackson-Lewis V, Lamba WR, Hayley SP, Grimm E, Callaghan SM, Slack RS, Melloni E, Przedborski S, Robertson GS, Anisman H, Merali Z, Park DS (2003) Inhibition of calpains prevents neuronal and behavioral deficits in an MPTP mouse model of Parkinson's disease. J Neurosci 23:4081-4091.

74. Chung YC, Kim SR, Jin BK (2010) Paroxetine prevents loss of nigrostriatal dopaminergic neurons by inhibiting brain inflammation and oxidative stress in an experimental model of Parkinson's disease. J Immunol 185:1230-1237.

75. West MJ (1999) Stereological methods for estimating the total number of neurons and synapses: issues of precision and bias. Trends Neurosci 22:51-61.

76. Sugama S, Yang L, Cho BP, DeGiorgio LA, Lorenzl S, Albers DS, Beal MF, Volpe BT, Joh TH (2003) Age-related microglial activation in 1-methyl-4-phenyl-1,2,3,6-tetrahydropyridine (MPTP)-induced dopaminergic neurodegeneration in C57BL/6 mice. Brain Res 964:288-294.

77. Gundersen HJ (1992) Stereology: the fast lane between neuroanatomy and brain function--or still only a tightrope? Acta Neurol Scand Suppl 137:8-13.

78. Diaz-Arrastia R, Wang KK, Papa L, Sorani MD, Yue JK, Puccio AM, McMahon PJ, Inoue T, Yuh EL, Lingsma HF, Maas AI,
Valadka AB, Okonkwo DO, Manley GT; TRACK-TBI Investigators (2014) Acute biomarkers of traumatic brain injury: relationship between plasma levels of ubiquitin C-terminal hydrolase-L1 and glial fibrillary acidic protein. J Neurotrauma 31:19-25.

79. Sariaslan A, Sharp DJ, D'Onofrio BM, Larsson H, Fazel S (2016) Long-term outcomes associated with traumatic brain injury in childhood and adolescence: a nationwide Swedish cohort study of a wide range of medical and social outcomes. PLoS Med 13:e1002103.

80. Scheid R, Walther K, Guthke T, Preul C, von Cramon DY (2006) Cognitive sequelae of diffuse axonal injury. Arch Neurol 63:418-424.

81. Bower JH, Maraganore DM, Peterson BJ, McDonnell SK, Ahlskog JE, Rocca WA (2003) Head trauma preceding PD: a case-control study. Neurology 60:1610-1615.

82. Goldman SM, Tanner CM, Oakes D, Bhudhikanok GS, Gupta A, Langston JW (2006) Head injury and Parkinson's disease risk in twins. Ann Neurol 60:65-72.

83. Uryu K, Giasson BI, Longhi L, Martinez D, Murray I, Conte V, Nakamura M, Saatman K, Talbot K, Horiguchi T, McIntosh T, Lee VM, Trojanowski JQ (2003) Age-dependent synuclein pathology following traumatic brain injury in mice. Exp Neurol 184:214-224.

84. Fann JR, Ribe AR, Pedersen HS, Fenger-Grøn M, Christensen J, Benros ME, Vestergaard M (2018) Long-term risk of dementia among people with traumatic brain injury in Denmark: a population-based observational cohort study. Lancet Psychiatry 5:424-431.

85. Walker WC, Pickett TC (2007) Motor impairment after severe traumatic brain injury: a longitudinal multicenter study. J Rehabil Res Dev 44:975-982.

86. McInnes K, Friesen CL, MacKenzie DE, Westwood DA, Boe SG (2017) Mild traumatic brain injury (mTBI) and chronic cognitive impairment: a scoping review. PLoS One 12:e0174847.

87. Katz DI, White DK, Alexander MP, Klein RB (2004) Recovery of ambulation after traumatic brain injury. Arch Phys Med Rehabil 85:865-869.

88. Swaine BR, Sullivan SJ (1996) Longitudinal profile of early motor recovery following severe traumatic brain injury. Brain Inj 10:347-366.

89. Carbonell WS, Maris DO, McCall T, Grady MS (1998) Adaptation of the fluid percussion injury model to the mouse. J Neurotrauma 15:217-229.

90. Spain A, Daumas S, Lifshitz J, Rhodes J, Andrews PJ, Horsburgh K, Fowler JH (2010) Mild fluid percussion injury in 
mice produces evolving selective axonal pathology and $\operatorname{cog}$ nitive deficits relevant to human brain injury. J Neurotrauma 27:1429-1438.

91. Shultz SR, Tan XL, Wright DK, Liu SJ, Semple BD, Johnston L, Jones NC, Cook AD, Hamilton JA, O'Brien TJ (2014) Granulocyte-macrophage colony-stimulating factor is neuroprotective in experimental traumatic brain injury. J Neurotrauma 31:976-983.

92. Wright DK, Trezise J, Kamnaksh A, Bekdash R, Johnston LA, Ordidge R, Semple BD, Gardner AJ, Stanwell P, O'Brien T), Agoston DV, Shultz SR (2016) Behavioral, blood, and magnetic resonance imaging biomarkers of experimental mild traumatic brain injury. Sci Rep 6:28713.

93. Wright DK, Liu S, van der Poel C, McDonald SJ, Brady RD, Taylor L, Yang L, Gardner AJ, Ordidge R, O'Brien TJ, Johnston LA, Shultz SR (2017) Traumatic brain injury results in cellular, structural and functional changes resembling motor neuron disease. Cereb Cortex 27:4503-4515.

94. Wallen MA, Mackay S, Duff SM, McCartney LC, O'flaherty SJ (2001) Upper-limb function in Australian children with traumatic brain injury: a controlled, prospective study. Arch Phys Med Rehabil 82:642-649.

95. Martini DN, Sabin MJ, DePesa SA, Leal EW, Negrete TN, Sosnoff JJ, Broglio SP (2011) The chronic effects of concussion on gait. Arch Phys Med Rehabil 92:585-589.

96. Jöhr J, Halimi F, Pasquier J, Pincherle A, Schiff N, Diserens K (2020) Recovery in cognitive motor dissociation after severe brain injury: a cohort study. PLoS One 15:e0228474.

97. Khan MM, Kempuraj D, Zaheer S, Zaheer A (2014) Glia maturation factor deficiency suppresses 1-methyl-4-phenylpyridinium-induced oxidative stress in astrocytes. J Mol Neurosci 53:590-599.

98. Berger RP (2006) The use of serum biomarkers to predict outcome after traumatic brain injury in adults and children. J Head Trauma Rehabil 21:315-333.

99. Ohrt-Nissen S, Friis-Hansen L, Dahl B, Stensballe J, Romner B, Rasmussen LS (2011) How does extracerebral trauma affect the clinical value of S100B measurements? Emerg Med J 28:941-944.

100. Mondello S, Linnet A, Buki A, Robicsek S, Gabrielli A, Tepas J, Papa L, Brophy GM, Tortella F, Hayes RL, Wang KK (2012) Clinical utility of serum levels of ubiquitin C-terminal hydrolase as a biomarker for severe traumatic brain injury. Neurosurgery 70:666-675.

101. Forde CT, Karri SK, Young AM, Ogilvy CS (2014) Predictive markers in traumatic brain injury: opportunities for a serum biosignature. Br J Neurosurg 28:8-15.
102. Dash PK, Zhao J, Hergenroeder G, Moore AN (2010) Biomarkers for the diagnosis, prognosis, and evaluation of treatment efficacy for traumatic brain injury. Neurotherapeutics 7:100-114.

103. Papa L, Silvestri S, Brophy GM, Giordano P, Falk JL, Braga CF, Tan CN, Ameli NJ, Demery JA, Dixit NK, Mendes ME, Hayes RL, Wang KK, Robertson CS (2014) GFAP out-performs $S 100 \beta$ in detecting traumatic intracranial lesions on computed tomography in trauma patients with mild traumatic brain injury and those with extracranial lesions. J Neurotrauma 31:1815-1822.

104. Honda M, Tsuruta R, Kaneko T, Kasaoka S, Yagi T, Todani M, Fujita M, Izumi T, Maekawa T (2010) Serum glial fibrillary acidic protein is a highly specific biomarker for traumatic brain injury in humans compared with S-100B and neuronspecific enolase. J Trauma 69:104-109.

105. Metting Z, Wilczak N, Rodiger LA, Schaaf JM, van der Naalt J (2012) GFAP and S100B in the acute phase of mild traumatic brain injury. Neurology 78:1428-1433.

106. Vos PE, Jacobs B, Andriessen TM, Lamers KJ, Borm GF, Beems T, Edwards M, Rosmalen CF, Vissers JL (2010) GFAP and $\mathrm{S100B}$ are biomarkers of traumatic brain injury: an observational cohort study. Neurology 75:1786-1793.

107. Pelinka LE, Kroepfl A, Leixnering M, Buchinger W, Raabe A, Redl H (2004) GFAP versus S100B in serum after traumatic brain injury: relationship to brain damage and outcome. J Neurotrauma 21:1553-1561.

108. Papa L, Akinyi L, Liu MC, Pineda JA, Tepas JJ 3rd, Oli MW, Zheng W, Robinson G, Robicsek SA, Gabrielli A, Heaton SC, Hannay HJ, Demery JA, Brophy GM, Layon J, Robertson CS, Hayes RL, Wang KK (2010) Ubiquitin C-terminal hydrolase is a novel biomarker in humans for severe traumatic brain injury. Crit Care Med 38:138-144.

109. Przedborski S (2007) Neuroinflammation and Parkinson's disease. Handb Clin Neurol 83:535-551.

110. Bourque MJ, Trudeau LE (2000) GDNF enhances the synaptic efficacy of dopaminergic neurons in culture. Eur J Neurosci 12:3172-3180.

111. Burke RE, Antonelli M, Sulzer D (1998) Glial cell line-derived neurotrophic growth factor inhibits apoptotic death of postnatal substantia nigra dopamine neurons in primary culture. J Neurochem 71:517-525.

112. Baquet ZC, Bickford PC, Jones KR (2005) Brain-derived neurotrophic factor is required for the establishment of the proper number of dopaminergic neurons in the substantia nigra pars compacta. J Neurosci 25:6251-6259.

113. von Bohlen und Halbach O, Minichiello L, Unsicker K (2005) 
Haploinsufficiency for trkB and trkC receptors induces cell loss and accumulation of alpha-synuclein in the substantia nigra. FASEB J 19:1740-1742.

114. Grandoso L, Ponce S, Manuel I, Arrúe A, Ruiz-Ortega JA, Ulibarri I, Orive G, Hernández RM, Rodríguez A, RodríguezPuertas R, Zumárraga M, Linazasoro G, Pedraz JL, Ugedo L (2007) Long-term survival of encapsulated GDNF secreting cells implanted within the striatum of parkinsonized rats. Int J Pharm 343:69-78.

115. Stahl K, Mylonakou MN, Skare Ø, Amiry-Moghaddam M, Torp R (2011) Cytoprotective effects of growth factors: BDNF more potent than GDNF in an organotypic culture model of Parkinson's disease. Brain Res 1378:105-118.

116. Impellizzeri D, Campolo M, Bruschetta G, Crupi R, Cordaro M, Paterniti I, Cuzzocrea S, Esposito E (2016) Traumatic brain injury leads to development of Parkinson's disease related pathology in mice. Front Neurosci 10:458.

117. Osterstock G, El Yandouzi T, RomanòN, Carmignac D, Langlet F, Coutry N, Guillou A, Schaeffer M, Chauvet N, Vanacker
C, Galibert E, Dehouck B, Robinson IC, Prévot V, Mollard P, Plesnila N, Méry PF (2014) Sustained alterations of hypothalamic tanycytes during posttraumatic hypopituitarism in male mice. Endocrinology 155:1887-1898.

118. Schneider HJ, Kreitschmann-Andermahr I, Ghigo E, Stalla GK, Agha A (2007) Hypothalamopituitary dysfunction following traumatic brain injury and aneurysmal subarachnoid hemorrhage: a systematic review. JAMA 298:1429-1438.

119. Tanriverdi F, Unluhizarci K, Kelestimur F (2010) Pituitary function in subjects with mild traumatic brain injury: a review of literature and proposal of a screening strategy. Pituitary 13:146-153.

120. Molaie AM, Maguire J (2018) Neuroendocrine abnormalities following traumatic brain injury: an important contributor to neuropsychiatric sequelae. Front Endocrinol (Lausanne) 9:176.

121. Greco T, Hovda D, Prins M (2013) The effects of repeat traumatic brain injury on the pituitary in adolescent rats. J Neurotrauma 30:1983-1990. 